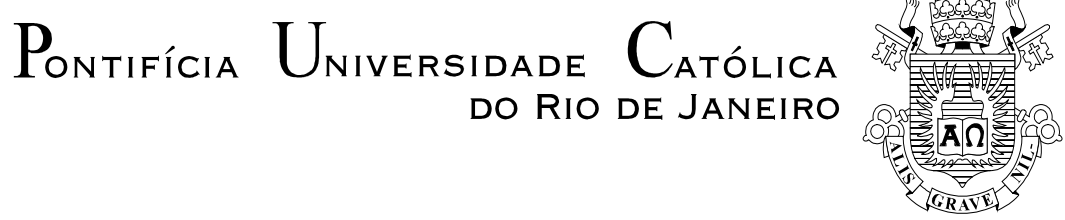

Viviane Teixeira Martins

Gestão de contratos para o afretamento de navios Estudo de caso em uma indústria de petróleo no Brasil

Orientador: Profa. Adriana Leiras

Dissertação apresentada como requisito parcial para obtenção de grau de Mestre pelo Programa de Pós-graduação em Engenharia de Produção do Departamento de Engenharia Industrial da PUCRio.

Rio de Janeiro

Novembro de 2015 


$$
\begin{aligned}
& \text { Pontifícia Universidade Católica } \\
& \text { DO RIO DE JANEIRO }
\end{aligned}
$$

Viviane Teixeira Martins

\section{Gestão de contratos para o afretamento de navios - Estudo de caso em uma indústria de petróleo no Brasil}

Dissertação apresentada como requisito parcial para obtenção do grau de Mestre (opção profissional) pelo Programa de Pós-graduação em Engenharia de Produção do Departamento de Engenharia Industrial do Centro Técnico Científico da PUC-Rio. Aprovada pela Comissão Examinadora abaixo assinada.

Profa. Adriana Leiras

Orientadora

Departamento de Engenharia Industrial - PUC-Rio

Prof. Hugo Miguel Varela Repolho Departamento de Engenharia Industrial - PUC-Rio

Prof. Orivalde Soares da Silva Júnior Departamento de Engenharia Industrial - PUC-Rio

José Eugênio Leal Coordenador Setorial do Centro Técnico Científico - PUC-Rio

Rio de Janeiro, 30 de novembro de 2015. 
Todos os direitos reservados. É proibida a reprodução total ou parcial do trabalho sem autorização da universidade, do autor e do orientador.

\section{Viviane Teixeira Martins}

Graduou-se em Engenharia Química na Universidade Estadual do Rio de Janeiro (UERJ) em 2004. Pós graduou-se em Engenharia de Processamento de Petróleo pela mesma universidade em 2007. Em 2008, graduou-se em Desenvolvimentos de Competências Logísticas pelo Instituto de Pós-Graduação e Pesquisa em Administração da Universidade Federal do Rio de Janeiro (COPPEAD/UFRJ). Após passagens profissionais pela Caixa Econômica Federal e pelo Tribunal de Contas do Estado do Rio de Janeiro, atualmente trabalha na Petrobras, onde atua como engenheira na área de Transporte Marítimo da Logística de Abastecimento da empresa.

Ficha Catalográfica

Martins, Viviane Teixeira

Gestão de contratos para o afretamento de navios: estudo de caso em uma indústria de petróleo no Brasil / Viviane Teixeira Martins; orientadora: Adriana Leiras. 2015.

85 f. : il. color. ; $30 \mathrm{~cm}$

Dissertação (mestrado)-Pontifícia Universidade Católica do Rio de Janeiro, Departamento de Engenharia Industrial, 2015.

Inclui bibliografia

1. Engenharia Industrial - Teses. 2. Suprimentos. 3. Compras. 4. Contratos. 5. Afretamento. I. Leiras, Adriana. II. Pontifícia Universidade Católica do Rio de Janeiro. Departamento de Engenharia Industrial. III. Título. 


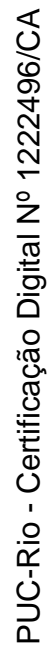

À minha filha Maria Lídia e aos meus sobrinhos Mateus e Rafaela 


\section{Agradecimentos}

A Deus por me encher de saúde e permitir que eu persiga meus sonhos.

Aos meus pais pelo incentivo em estudar em todos os momentos da minha vida.

A todos os meus amigos e familiares que me ajudaram a seguir em frente quando os obstáculos pareciam intransponíveis.

Ao Gabriel pelo amor e apoio nas horas em que as dificuldades traziam desânimo e cansaço.

Ao Jordi que esteve sempre ao meu lado nos inúmeros fins de semana de estudo.

Aos meus colegas da Petrobras que tanto me auxiliaram na elaboração do estudo de caso.

Ao meu coordenador Francisco Figueiredo e ao meu gerente Carlos Guimarães por permitirem que esse estudo tenha sido concluído. 


\section{Resumo}

Martins, Viviane Teixeira; Leiras, Adriana. Gestão de contratos para o afretamento de navios - Estudo de caso em uma indústria de petróleo no Brasil. Rio de Janeiro, 2015. 85p. Dissertação de Mestrado (Opção profissional) - Departamento de Engenharia Industrial, Pontifícia Universidade Católica do Rio de Janeiro.

Nos dias atuais, as empresas vêm tratando a questão logística de forma estratégica, ou seja, ao invés de otimizar pontualmente as operações, focalizando os procedimentos logísticos como meros geradores de custo, as empresas participantes da cadeia de suprimento passaram a buscar soluções novas, usando a logística para ganhar competitividade e também para induzir novos negócios. Desta forma, há uma nova concepção no tratamento dos problemas logísticos: o gerenciamento da cadeia de suprimento (supply chain management - SCM). Dentro dos processos contidos na gestão da cadeia de suprimento, a área de compras sofreu um grande avanço em termos de pesquisa dentro do mundo acadêmico. O conhecimento dos mercados fornecedores, as habilidades de compras, a busca por alternativas de suprimento e a disponibilidade dos recursos para o processo de compra fazem com que a função Compras exerça um papel cada vez mais estratégico dentro das empresas. O objetivo deste trabalho é propor uma matriz de estratégia de compras do modelo de Kraljic (1983) para o afretamento de navios na logística de abastecimento de uma empresa verticalizada de petróleo no Brasil. Para isto, o trabalho descreveu as peculiaridades do processo de afretamento, além de analisar e posicionar os contratos na matriz de portfólio de Kraljic (1983) para o afretamento nessa empresa. O estudo analisou o retrato atual da gestão dos contratos de afretamento adotados na empresa e aplicou os conceitos do estudo de Kraljic nesses contratos. Concluiu-se que alguns contratos da empresa fazem parte do quadrante de alavancagem, outros do quadrante estratégico e outros do quadrante de itens não críticos da matriz de Kraljic (1983), e, para cada um desses quadrantes, foram identificados os possíveis riscos e as necessidades de ajustes nos processos. Dessa forma, o estudo 
fez recomendações para a empresa de como atuar na gestão desses contratos considerando os conceitos da literatura atual sobre o assunto.

\section{Palavras-chave}

Suprimentos; compras; contratos; afretamento. 


\section{Abstract}

Martins, Viviane Teixeira; Leiras, Adriana (Advisor). Contract management for the charter of vessels - Case Study on an oil industry in Brazil. Rio de Janeiro, 2015. 85. MSc. Dissertation - Departamento de Engenharia Industrial, Pontifícia Universidade Católica do Rio de Janeiro.

Nowadays, companies deal with logistics in a strategical way, in other words, instead of promptly optimize operations, focusing on the logistical procedures as mere cost drivers, supply chain companies are now looking for new solutions using logistics to gain competitiveness and also to induce new business. Thus, there is a new concept in the treatment of logistical matters: the supply chain management (SCM). One of the processes in supply chain management, the purchasing area suffered a major breakthrough in terms of research in academia. Knowledge of supplier markets, purchasing skills, searching for alternative supply sources and availability of resources for the purchasing process make the purchasing function plays strategic role increasingly strategic in companies. The objective of this research is to propose a Kraljic purchasing strategy matrix (1983) to vessels chartering on the supply chain of an oil company in Brazil. For this purpose, the peculiarities of the chartering process of this company is described and analyzed, and the contracts are positioned in the Kraljic portfolio matrix (1983). The study analyzed the current management situation of the charter processes adopted in company and applied the concepts of Kraljic study on these contracts. It was concluded that some of the company contracts are part of the leverage quadrant whereas others are part of strategic quadrant, and others of noncritical items quadrant of Kraljic matrix (1983). For each of these quadrants, possible risks and adjustment needs have been identified in the process. Thus, the study made recommendations to the company how to act in the management of these contracts considering the concepts of the current literature on the subject.

\section{Keywords}

Supply; purchasing; contracts; chartering. 


\section{Sumário}

1 Introdução 13

1.1. Objetivos 15

1.2. Metodologia 15

1.3. Estrutura da dissertação 16

2 Fundamentação Teórica 18

2.1. Gestão da cadeia de suprimento (SCM - Supply Chain Management) 18

2.2. Compras 23

2.3. A decisão de fazer ou comprar 25

2.4. Estratégia de Compras 28

2.5. Análise de Portfólio de Kraljic 33

3 Visão geral do Transporte Marítimo (Shipping) 41

3.1. Transporte Marítimo

3.2. Afretamento 45

3.3. Estratégia de compras no transporte marítimo $\quad 47$

4 Estudo de caso $\quad 49$

4.1. O Transporte Marítimo na Empresa XYZ 49

4.2. Metodologia de condução do estudo de caso 51

4.3. Resultados 53

4.3.1. Critérios para definição dos agrupamentos 53

4.3.2. Análise dos eixos $\quad 56$

4.3.3. O posicionamento na Matriz de Kraljic 57

4.4. Análise dos resultados 62

4.4.1. Fase 1 - Classificação dos requisitos da contratação 63

4.4.2. Fase 2 - Análise de mercado 64

4.4.3. Fase 3 - Posicionamento estratégico 65

4.4.4. Fase 4 - Planos de ação 67

5 Conclusões e Recomendações $\quad 68$

5.1. Recomendações para Estudos Futuros 70

6 Referências bibliográficas $\quad 71$ 
Apêndice I

Lista de navios com os valores percentuais de cada navio em relação ao valor total contratado em TCP em análise neste estudo:

Apêndice II

82

Tabela de navios com posicionamento dos armadores na Matriz de Kraljic: 


\section{Lista de figuras}

Figura 1 Estrutura da gestão da cadeia de suprimento 21

Figura 2 Aspectos analisados a favor do comprar e do fazer 27

Figura 3 Classificação das atividades de uma empresa 28

Figura 4 Estratégias de compra em função da fonte de poder do fornecedor 30

Figura 5 Estrutura de poder comprador-fornecedor 31

Figura 6 Estágios de Sofisticação de Compras 35

Figura 7 Classificação dos itens 36

Figura 8 Posicionamento dos itens de compra 37

Figura 9 Fatores para Avaliação da Força do Comprador e do Fornecedor 38

Figura 10 Matriz de portfolio de compras 39

Figura 11 Implicações das Posições Estratégicas Escolhidas 40

Figura 12 Diagrama de passos do estudo de caso 52

Figura 13 Agrupamento por tipo de contratação e por armador 55

Figura 14 Agrupamento por tipo de contratação e por classe 56

Figura 15 Posicionamento na matriz segundo proposta de classificação dos eixos $\quad 57$

Figura 16 Gráfico com principais armadores dos contratos em TCP 58

Figura 17 Posicionamento dos contratos na Matriz de Kraljic 60

Figura 18 Itens posicionados como estratégicos na Matriz de Kraljic (1983) 66 


\section{Lista de tabelas}

Tabela 1 Classificação dos Navios de petróleo e derivados quanto ao porte $\quad 44$

Tabela 2 Classificação dos navios de derivados claros quanto ao porte $\quad 44$

Tabela 3 Agrupamento por classes de navio 54

Tabela 4 Classe do navio e letra correspondente 55 


\section{1 \\ Introdução}

Nos dias atuais, devido ao aumento da competitividade empresarial, as organizações foram e estão sendo forçadas a se tornarem mais ágeis, inovadoras, e a entregar produtos de alta qualidade dentro de prazos mais curtos, e ainda sendo capazes de reduzir os custos dessas transações (MIKALEF et al., 2013). Ademais, o mundo corporativo passou da condição de competição entre empresas de forma isolada para uma competição entre cadeias de suprimento (LAMBERT \& COOPER, 2000; PIRES, 2004), fato que fez com que o gerenciamento desta cadeia passasse a ser fundamental para gerar vantagem competitiva.

Verifica-se também um grande aumento nas operações globais de compra e venda de produtos e serviços, fazendo com que as empresas multinacionais sejam obrigadas a fazer investimentos em novas fábricas, transferir tecnologias entre unidades e reavaliar a gestão da cadeia de suprimento. Também se pode mencionar que este ambiente empresarial gera a necessidade de um aprofundamento maior nos temas ligados à gestão de operações internacionais, tanto por parte da academia como dos profissionais que estão na linha de frente das ações organizacionais (PRASAD E BABBAR, 2000).

Com o advento dessas mudanças no âmbito empresarial, as atividades em uma organização deixaram de ser vistas em termos de funções e departamentos para serem tratadas em termos de processos gerenciados de forma integrada inter e intra-empresas, dentro da cadeia de suprimento. No entanto, isso não significa que a estrutura funcional foi substituída por processos, já que o conhecimento necessário e a realização das atividades de um processo ocorrem dentro das estruturas organizacionais, porém não ocorrem totalmente em apenas uma delas (LAMBERT, 2004).

Assim, pode-se observar que as estruturas de SCM (supply chain management - em português: gestão da cadeia de suprimentos) apresentadas na literatura têm, em comum, um processo relacionado à aquisição de materiais: Compras; Relacionamento com Fornecedores; Aquisição e Abastecimento (LAMBERT, 2004). Nesse contexto, a função compra deixou de ter como papel 
principal a obtenção de bens e serviços em resposta a solicitações de usuários internos e passou a ser uma atividade importante para que a organização atinja seus objetivos estratégicos, na busca de maior competitividade (LAMBERT \& COOPER, 2000; CROXTON et al., 2001).

Prasad e Babbar (2000) afirmam que, para competir no mercado internacional, as empresas precisam adequar suas operações globais de compras, logística e produção à realidade da região na qual realizam suas operações. Nesse ambiente, as áreas de logística e compras têm recebido especial atenção nas organizações, pois ambas têm um bom potencial para proporcionarem redução de custos das empresas (ELLRAM, 2002; ASHENBAUM, 2006) ou gerarem alguma vantagem competitiva via melhoria de serviços (ELLRAM, 2002).

A função Compras é geralmente a primeira interface da empresa com seus fornecedores e sua importância para a organização se evidencia no fato que as compras externas representam cerca de $60 \%$ do custo de venda do produto, no caso de empresas produtoras de bens, e $25 \%$ para organizações que atuam na prestação de serviços (ELLRAM, 2002).

O presente trabalho trata de um estudo de caso sobre a estratégia de compras de afretamento de navios considerando o mercado internacional de petróleo, a ser aplicado em uma empresa integrada e verticalizada de energia (aqui chamada de $\mathrm{XYZ}$ ), que atua primordialmente desde a exploração e produção do petróleo até a venda de petróleo e seus produtos derivados aos distribuidores e clientes internacionais.

Para a academia, o presente estudo disponibiliza informações e análises sobre o afretamento de navios e todo o mundo envolvido na contratação de transporte marítimo. $O$ trabalho também pode ajudar a empresa a gerir e analisar os seus procedimentos internos considerando os modelos propostos pela literatura, como o modelo de Kraljic (1983). O trabalho demonstra, assim, sua importância, tendo em vista não terem sido encontrados na literatura estudos que correlacionem estratégia de compras com o mercado de prestação de serviço de transporte marítimo. 


\section{1. \\ Objetivos}

O objetivo principal deste trabalho é propor uma matriz de estratégia de compras do modelo de Kraljic (1983) para o afretamento de navios na logística de abastecimento de uma empresa verticalizada de petróleo no Brasil. A matriz de Kraljic (1983) é aplicada como modelo de portfólio, por ter sido o primeiro modelo de portfólio de compras e por ainda ser uma referência nos dias atuais, para definir qual estratégia de compras deve ser adotada.

Para isto, esse trabalho possui os seguintes objetivos específicos:

i. Identificar e descrever as peculiaridades do processo de afretamento de navios em uma empresa de petróleo.

ii. Analisar e posicionar os contratos na matriz de portfólio de Kraljic para o afretamento de navios nessa empresa, classificando os tipos de afretamento e os posicionando nos quadrantes da matriz;

\section{2. Metodologia}

A metodologia de pesquisa utilizada para analisar o presente estudo seguirá o critério de classificação de pesquisa proposto por Vergara (2005), quanto aos fins, quanto aos meios e quanto à abordagem.

Quanto aos fins, trata-se de uma pesquisa descritiva, pois pretende analisar a estratégia de compras do processo de afretamento de navios. Segundo Vergara (2005), tal classificação expõe características de determinada população ou de determinado fenômeno. Pode também estabelecer correlações entre variáveis e definir sua natureza. Não tem compromisso de explicar os fenômenos que descreve, embora sirva de base para tal explicação.

Também segundo Vergara (2005), quanto aos meios, trata-se de pesquisa bibliográfica e estudo de caso. Bibliográfica, porque a fundamentação teórica foi obtida a partir de pesquisas em material publicado em livros, revistas, jornais, redes eletrônicas, isto é, material acessível ao público em geral. É um estudo de caso pois está circunscrito a uma ou poucas unidades, entendidas essas como pessoa, família, produto, empresa, organização, comunidade ou mesmo país. Nessa classificação se encontra o estudo de caso, com uso de questionário, usado nesse estudo. 
$\mathrm{E}$, em relação à abordagem, trata-se de um estudo qualitativo. De acordo com Vergara (2005), um estudo é qualitativo quando utiliza as informações e dados obtidos sem medição numérica para levantar ou refinar perguntas no processo de interpretação. Os dados qualitativos constituem descrições detalhadas de situações, eventos, pessoas, interações condutas observadas e suas manifestações. A interpretação dos fenômenos e a atribuição de significados são básicas no processo de pesquisa qualitativa.

$\mathrm{Na}$ fase de estruturação do estudo de caso, Yin (2005) relata que existem pelo menos três etapas: a primeira abrange as referências teóricas sobre as quais se pretende estudar, a seleção dos casos e o desenvolvimento de protocolos para obtenção dos casos, tais como, observação de campo, entrevistas, análise de documentos etc. A segunda compreende a coleta dos dados propriamente dita, a análise desses dados e a elaboração do relatório dos dados. E a terceira fase trata da análise dos dados encontrados à luz da teoria escolhida, com interpretação e futura conclusão do estudo.

\section{3. \\ Estrutura da dissertação}

Visando facilitar o entendimento do estudo, a presente dissertação está organizada em cinco capítulos, sendo este primeiro o introdutório.

O segundo capítulo apresenta uma fundamentação teórica obtida na literatura que conduz o leitor ao assunto tema desse trabalho, iniciando nos conceitos da gestão da cadeia de suprimento, que tem como um de seus processos principais a função Compras. Parte-se então para o questionamento que as empresas enfrentam de fazer ou comprar para então chegar à estratégia de compras e o modelo de portfólio de Kraljic, tema central da dissertação.

Após a revisão da literatura referente aos principais conceitos, o terceiro capítulo faz uma apresentação sobre o transporte marítimo, sobre todo o seu universo de definições e características de contratação extremamente particular.

O quarto capítulo trata da descrição do estudo de caso realizado. O capítulo inicia-se com a descrição sobre os o afretamento de navios e sua importância dentro da empresa XYZ. Posteriormente, relaciona os aspectos dos tipos de afretamento com a matriz de Kraljic para fundamentar a análise do estudo de caso, entrevistando funcionários da área afim da empresa XYZ e, então, finalmente consolida os dados encontrados. 
O quinto e último capítulo apresenta a conclusão do estudo identificando os aspectos afins entre teoria e prática.

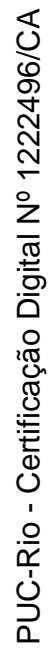




\section{2 \\ Fundamentação Teórica}

Neste capítulo são descritos os conceitos de gestão da cadeia de suprimento e de como a função compras se insere neste conceito.

Para isto, o capítulo é dividido em cinco seções: a primeira expõe o conceito da gestão da cadeia de suprimento; a segunda, sobre a função compras, aborda a decisão entre fazer e comprar e a estratégia de compras; a terceira situa a função compras na cadeia de suprimento, a quarta seção apresenta o conceito dos modelos de gestão compras e a quinta e última descreve o modelo da análise de portfólio de Kraljic,

\section{1. Gestão da cadeia de suprimento (SCM - Supply Chain Management)}

Segundo Novaes (2007), nos dias atuais as empresas vêm tratando a questão logística de forma estratégica, ou seja, em lugar de otimizar pontualmente as operações, focalizando os procedimentos logísticos como meros geradores de custo, as empresas participantes da cadeia de suprimento passaram a buscar soluções novas, usando a logística para ganhar competitividade e para induzir novos negócios. Dessa maneira, nesta nova fase, há o surgimento de uma nova concepção no tratamento dos problemas logísticos: o gerenciamento da cadeia de suprimento (supply chain management - SCM).

Uma cadeia de suprimento engloba todas as partes envolvidas, direta ou indiretamente, no atendimento de um pedido ao cliente. A cadeia de suprimento inclui produtores, fornecedores, transportadores, armazéns, varejistas e até mesmo os próprios clientes (SUKATI et al., 2012). Assim, nessa nova abordagem, a integração entre os processos ao longo da cadeia de suprimento continua a ser feita em termos de materiais,informação e dinheiro, mas, agora, os agentes participantes atuam em uníssono e de forma estratégica (NOVAES, 2007). Dessa forma, há uma quebra de fronteiras entre as áreas; a separação não é mais nítida, a integração é plena, estratégica e flexível ao longo de toda a cadeia de suprimento. 
Segundo Lambert (2004), é importante definir o que é a gestão da cadeia de suprimento, pois o termo ainda se confunde com o termo logística, ou mesmo como sendo uma logística que inclui clientes e fornecedores.

Logística, de acordo com a definição de 1998 do Council of Logistics Management, é uma parte do processo da cadeia de suprimento que planeja, implementa e controla fluxos e estoques, eficientes e eficazes, de materiais, serviços e informações relacionadas, desde o ponto de origem até o ponto de consumo, com o objetivo de atender às necessidades dos clientes (LAMBERT \& COOPER, 2000).

Lambert (2004) considera em seu trabalho a definição para SCM do Global Supply Chain Forum (GSCF),

"Gestão da cadeia de suprimento é a integração de processos-chave existentes desde o usuário final até os fornecedores primários, que produzem produtos, serviços e informações que agreguem valor aos clientes e às demais partes envolvidas, os stakeholders." (LAMBERT, 2004).

Desta forma, comparando-se com a logística, entende-se que a gestão da cadeia de suprimento se faz de forma ainda mais integrada e com todos os processos-chave da empresa. Ademais, para que essa gestão tenha sucesso, é necessária uma mudança de gerir individualmente os departamentos (ou funções) para gerir um grupo integrado de processos (LAMBERT, 2004).

Para Bowersox et al. (2007), a gestão da cadeia de suprimento consiste na colaboração entre empresas para impulsionar o posicionamento estratégico e para melhorar a eficiência operacional. As operações da cadeia de suprimento exigem processos gerenciais que atravessam as áreas funcionais de cada empresa e conectam parceiros comerciais e clientes para além das fronteiras organizacionais.

Para Lambert \& Cooper (2000), a mais significante mudança de paradigma na gestão de negócios nos tempos atuais é que as empresas passaram de uma condição de competição entre empresas, de forma isolada, para uma competição entre cadeias de suprimento. E assim, o sucesso de uma empresa depende da capacidade de gerenciar uma intrincada rede de relacionamentos de negócios.

Segundo Miocevic (2011), a gestão da cadeia de suprimento se tornou um campo de diversas abordagens acadêmicas. O sucesso da cadeia de suprimento depende da habilidade de integrar os muitos objetivos e estratégias de cada membro da cadeia. Esforços de integração são exequíveis por meio do 
desenvolvimento de relações entre os meios da cadeia. $E$ esses esforços justificam a valorização da função de cada parceiro a montante e a jusante.

Chow et al. (2008) entendem que a gestão da cadeia de suprimentos é uma aproximação holística entre a gestão dos processos de demanda, suprimento e compras, produção e logística. É uma rede que consiste de todas as partes envolvidas diretamente ou indiretamente, que inclui produtor, fornecedor, distribuidor e vendedor para produção e entrega de produtos ou serviços aos consumidores finais através da distribuição física, fluxo de informação e finanças (STOCK \& BOYER, 2009). Como a gestão da cadeia de suprimentos está passando por uma transformação avassaladora e evoluindo muito rapidamente (MELNIK et al. 2009), seu conceito moderno na nova economia incorpora diferenciação estratégica, melhoria da eficiência operacional, redução de custos; além da integração da cadeia de suprimentos e cadeias de suprimentos virtuais (CHOW et al., 2008).

Esse entendimento amplo de gestão da cadeia de suprimento é ilustrado na Figura 1, que retrata uma estrutura simplificada da rede da cadeia de suprimento; os fluxos de informação e produto; e os processos-chave da cadeia de suprimento penetrando os departamentos funcionais dentro da empresa e os vários silos corporativos através da cadeia de suprimento (LAMBERT et al., 1998). 


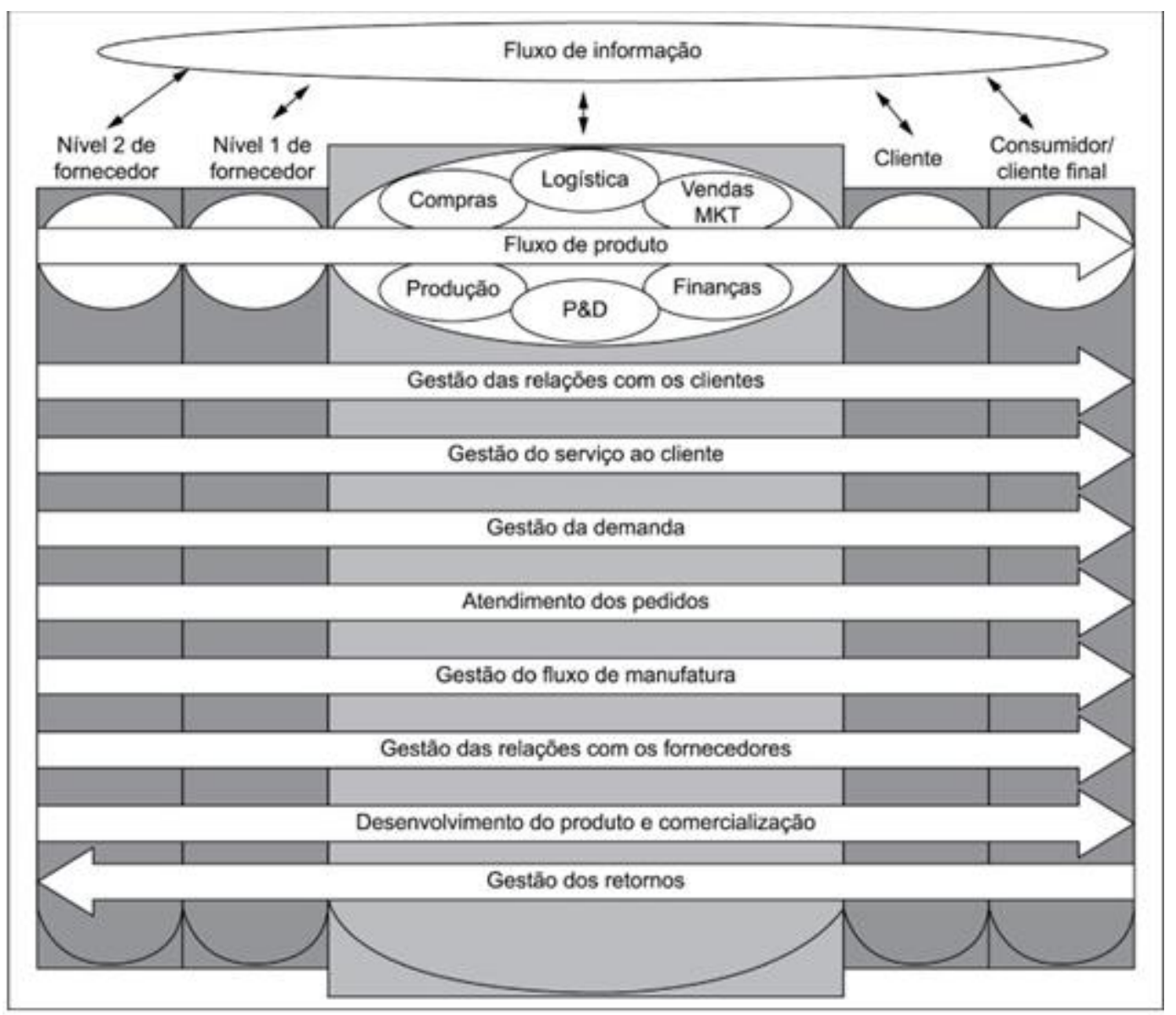

\section{Figura 1 Estrutura da gestão da cadeia de suprimento}

Fonte: Lambert et al. (1998).

Lambert \& Cooper (2000) classificam como processos chaves na cadeia de suprimento: o gerenciamento do relacionamento com clientes; as compras; o gerenciamento de serviços ao cliente; o gerenciamento da demanda; o atendimento de pedidos; o gerenciamento do fluxo de produção; o desenvolvimento de produtos e comercialização; e o retorno. Cada um desses processos é descrito a seguir.

- Gerenciamento do relacionamento com clientes - A primeira etapa é a identificação dos clientes chaves e grupos de clientes os quais a organização entende serem críticos para o sucesso do negócio. Após a identificação dos clientes ou grupos de clientes críticos, são elaborados acordos para fornecimento de produtos e serviços, com especificação do nível de desempenho desejado;

- Serviços ao cliente - Ponto chave na administração dos acordos de fornecimento de produtos e serviços proporciona informações em tempo real sobre previsões de entrega e disponibilidade de produtos.; 
- Gerenciamento da Demanda - Sua finalidade é buscar o equilíbrio entre os requisitos do cliente e a capacidade de fornecimento da empresa, visando obter um maior controle do nível de estoque.

- Atendimento a pedidos - Para alcançar uma elevada taxa de atendimento de pedidos, é necessária uma efetiva integração das atividades de planejamento da produção, distribuição e transporte da empresa. A redução de custos de entrega, porém, está relacionada à realização de alianças com membros chaves da cadeia de suprimento;

- Gerenciamento do fluxo de produção - Ao longo da história corporativa, as empresas produziam e enviavam seus produtos aos canais de distribuição baseadas no histórico de demanda. Com a gestão da cadeia de suprimento, a produção é baseada na necessidade do cliente e os pedidos são emitidos just-intime (JIT) em lotes mínimos;

- Desenvolvimento de produtos e comercialização - Em empresas em que o desenvolvimento de novos produtos é crucial, clientes e fornecedores precisam estar integrados ao processo de desenvolvimento. Para que isso aconteça, gerentes de desenvolvimento de produtos devem estar integrados com a gerência de relacionamento com clientes, com o intuito de identificar suas necessidades e desenvolver tecnologia de produção dentro do fluxo de produção;

- Gestão dos retornos - Oferece oportunidade de melhoria de produtividade e de avanços de projetos, estabelecendo uma verdadeira vantagem competitiva;

- Compras - Com o objetivo de sustentar o fluxo de produção, são desenvolvidos planos estratégicos com fornecedores e celebrados contratos de longa duração com um pequeno grupo de fornecedores considerados de vital importância para organização. Pode ser estabelecida, dessa forma, uma relação ganha-ganha, embora nem sempre isso venha a acontecer. Além de atuar em relacionamento com fornecedores, o processo de compras busca eficiência através da redução dos custos de transação e redução de tempo, com a utilização de mecanismos de comunicação rápida, como por exemplo, transmissão eletrônica de dados (EDI - Eletronic Data Interchange) e comunicação via Internet.

Sendo o processo de compras o foco deste trabalho, ele será detalhado na seção 2.2 . 


\section{2. \\ Compras}

Um ponto comum na definição dos processos de gestão da cadeia de suprimentos é a existência de um processo relacionado à aquisição de materiais de forma explícita, ratificando a importância deste processo (LAMBERT, 2004).

Lysons \& Farrington (2006) declaram que o estudo sobre compra pode ter várias perspectivas: de função; de processo; de elo na cadeia de suprimento ou de valor; de relacionamento; de disciplina; e de profissão. Neste trabalho, será adotada uma abordagem de compra como função, como processo e como elo na cadeia de suprimento.

O modelo das cinco forças de Porter (1979) pode ser considerado relevante para o reconhecimento da função de Compras como função estratégica, na medida em que reconhece os fornecedores como uma das forças do mercado. ELLRAM \& CARR (1994) consideram que a função Compras possui um papel-chave para o sucesso de uma organização: é responsável pela seleção e desenvolvimento dos fornecedores que servirão de base para 0 crescimento da empresa no longo prazo. Além disto, Compras tem ação direta na redução dos custos de aquisição dos insumos de produção.

Ainda para Carr \& Smeltzer (2000), o conhecimento dos mercados fornecedores, as habilidades de compras, a busca por alternativas de suprimento e a disponibilidade dos recursos para o processo de compra, fazem com que a função Compras exerça um papel estratégico dentro das empresas.

O processo de compra é um conjunto de sub-processos com o objetivo de prover materiais e serviços a uma organização. Normalmente, a coordenação e execução das atividades do processo de compra ocorrem dentro da função compra: pessoas, com conhecimentos e habilidades específicas, utilizam recursos para desempenhar a atividade de comprar (LYSONS \& FARRINGTON, 2006).

A função compra tem seis objetivos básicos para que seja atingido um desempenho de "classe mundial": suporte às necessidades operacionais; gerenciamento do processo de compras de forma eficiente e eficaz; gerenciamento da base de suprimento; desenvolvimento de relacionamentos fortes com outros grupos funcionais da organização; suporte às metas e objetivos organizacionais; e desenvolvimento de estratégias integradas de compras que deem suporte às estratégias organizacionais (MONCKZA ET AL., 2005). 
Para que esses objetivos sejam atingidos, são adotadas diferentes abordagens em função da importância estratégica do material para a organização e da complexidade do mercado fornecedor. Para isso, o nível estratégico da organização define estratégias de compra em um plano de ação que deve ser executado pelo nível operacional da organização. Portanto, a execução do plano de ação de compra assume um papel decisivo na obtenção da competitividade necessária para manter a empresa no mercado e atender aos interesses das partes (NELLORE \& SÖDERQUIST, 2000).

A crescente ênfase que as organizações estão dando na função compras e na gestão da cadeia de suprimento ao longo da ultima década tem virado o foco das atenções para o potencial dos sistemas eletrônicos de compras (e-compras). A adoção de sistemas eletrônicos de compras vem sendo sujeito de muita atenção com um largo número de estudos estressando seus benefícios potenciais, que incluem baixos custos de compra, alta qualidade dos produtos comprados, melhor relacionamento com os fornecedores e muito mais (MIKALEF et al., 2013).

Pode-se identificar também que a globalização, a terceirização e o comércio eletrônico são fatores chave que fazem mudanças rápidas e substanciais na situação da atividade de compras, dos papéis de cada atividade em compras e na estrutura da organização (ZHENG et al., 2007). Além disso, vários estudos apontam para uma redução da importância do que pode ser considerado como habilidades mais técnicas em compras e para a crescente importância de habilidades mais genéricas, "maleáveis" e estratégicas (KNIGHT, et al., 2014).

Observa-se ainda que escritórios internacionais de compras (international purchasing offices - IPOs) de empresas multinacionais atualmente exercem papéis importantes no crescimento das atividades internacionais de suprimento em economias de países envolvidos e em desenvolvimento. Os IPOs vêm sendo considerados uma parte de, ou um passo importante para os processos globais de compra dessas multinacionais (JIA et al., 2014). Monczka et al. (2008) observaram que a criação formal de um IPO é um fator crítico para o sucesso da gestão de suprimento integrado global e que isso se tornou umas das mais frequentes estratégias para a gestão internacional das atividades de suprimento.

Quanto ao aspecto da compra de serviços, ou seja, da contratação de serviços, Pemer et al. (2014) afirmam que tais contratações vêm representando uma proporção crescente dos custos das organizações. 
De acordo com Metters (2008), uma conclusão implícita de estudos anteriores sobre a função compras é a universalidade cultural, isto é, que práticas e abordagens identificadas são válidas em diferentes contextos culturais. O pressuposto da existência de uma universalidade cultural é suportado por pesquisas de compras e gestão de suprimento (purchasing and supply management - PSM), que têm revelado que companhias em diversos contextos culturais diferem em relação a, por exemplo, suas decisões de terceirizações e de compras, e também as relações entre comprador e fornecedor (CANNON et al., 2010).

No entanto, essas descobertas em relação à influência da cultura nacional nos processos de compra vêm de um contexto de não-serviços. As práticas de compra de serviços diferem da compra de bens, pois serviços são contratados considerando qualidade intangíveis, além de dependerem da confiança e da relação comprador-vendedor (SMEDLUND, 2008; WHEILER, 1987). Essas características tornam tais práticas sensíveis especificamente a diferenças culturais, já que são demasiadamente subjetivas e dependentes da percepção particular de cada parte envolvida (VOLDNES et al., 2012; WHEILER, 1987), que estão culturalmente arraigadas. Por essa razão, conclusões sobre a influência da cultura nacional na compra de bens manufaturados não podem ser diretamente transferidas para a contratação de serviços (PEMER et al., 2014).

\section{3.}

\section{A decisão de fazer ou comprar}

Atualmente, a necessidade das companhias desenvolverem estratégias de produção está bastante consagrada. Uma questão fundamental no desenvolvimento de uma estratégia de produção é a determinação do que a companhia vai fazer e do que vai comprar, ou seja, a decisão de fazer ou comprar. Historicamente, tais decisões eram frequentemente tomadas baseadas em custo. No entanto, nos últimos anos, está aumentando o reconhecimento das implicações estratégicas dessas decisões e também da necessidade de se considerar uma grande gama de outros fatores além do custo (PLATTS et al., 2002). Para Nellore et al. (2000), a decisão de terceirizar uma atividade em oposição a realizá-la internamente e o desenvolvimento de uma peça ou sistema de peças é uma das decisões mais complexas enfrentadas pelos gestores industriais. 
Para Dubois (2003), a área de suprimento nas companhias vem se tornando cada vez mais importante ao longo das últimas décadas. Uma razão é que os custos dos bens de consumo e do serviço representam a maior parte dos custos totais de uma empresa. Atribui-se a esse elevado percentual, a vontade das empresas em concentrar mais esforços em uma parte limitada (competência central) da estrutura global das atividades da rede de negócios em que está inserida. Terceirizando as atividades a fornecedores externos, estão mais disponíveis para se especializarem em sua suas próprias operações. Outra razão do aumento dessa importância é o crescimento significativo de interfaces com outras empresas.

De acordo com Arya et al. (2005), em discussões didáticas sobre a questão "fazer ou comprar", a terceirização é frequentemente justificada em bases tecnológicas. Ou seja, fornecedores provavelmente devem ter equipamentos melhores, maior capacidade, ou vantagens de economia de escala. No entanto, mesmo quando aspectos tecnológicos estão ausentes, a terceirização pode ser preferida. A vantagem em terceirizar surge porque o preço estabelecido por um fornecedor, com seus interesses próprios, pode transferir informações para o comprador. E tal informação transmitida permite a empresa ajustar melhor sua produção em cada circunstância.

Dobler \& Burt (1996) consideram que quando uma empresa avalia que componentes ou subsistemas devem ser feitos e quais devem ser comprados, ou seja, a decisão entre fazer ou comprar, tal decisão deve se basear em dois aspectos: estratégico e tático.

O ponto de partida para a análise do ponto de vista estratégico é a identificação dos pontos fortes da empresa. Uma investigação minuciosa sobre questões relativas a essa identificação é o que se chama de identificação das competências centrais (core competences) existentes. O segundo passo é conhecer o cenário atual e o futuro em que a empresa opera. Assim, será possível identificar quais as competências necessárias para operar no futuro. Uma regra muito utilizada é a compra de subsistemas e componentes, exceto se se enquadrarem em uma das situações:

- Item crítico para o sucesso do produto, incluindo a percepção do cliente para um atributo importante do produto;

- Item que requer projeto especializado e habilidade de manufatura ou equipamento; 
- Item que se enquadra em uma das competências centrais da empresa, ou em uma das que é preciso desenvolver para atender aos planos futuros (DOBLER \& BURT, 1996).

Nas considerações sobre o que fazer e o que comprar, então, as decisões devem explorar as competências centrais da empresa. Os itens que devem ser feitos na empresa devem ser aqueles que requerem as habilidades que estão fortemente ligadas com as competências centrais da empresa e que as reforçam mutuamente. Essa é a consideração do aspecto estratégico que orienta as decisões iniciais de fazer-ou-comprar que, então, modelam a natureza da empresa (DOBLER \& BURT, 1996).

Após a análise da decisão estratégica entre comprar ou fazer, do ponto de vista tático/operacional, os aspectos custo e capacidade disponível de manufatura se destacam sobre todos os outros na decisão de fazer ou comprar. Porém, outros aspectos devem ser analisados e classificados em aqueles que são a favor de "fazer" e aqueles que são a favor do "comprar", conforme o quadro 1.

\begin{tabular}{|l|l|}
\hline \multicolumn{1}{|c|}{ A favor do "fazer" } & \multicolumn{1}{|c|}{ A favor do "comprar" } \\
\hline •Condições de custo - é mais barato fazer & •Pesquisa e know-how especializado do \\
do que comprar; & fornecedor; \\
•Desejo de integrar plantas de produção; & •Custo (mais barato comprar do que \\
•Utilização produtiva de capacidade em & fazer); \\
excesso da planta para ajudar absorver os & •Necessidade de pequeno volume do \\
custos fixos; & produto; \\
•Necessidade de exercer controle direto & •Facilidades de produção limitadas; \\
na produção ou qualidade do produto; & •Desejo de manter uma força de trabalho \\
•Requisito de sigilo de projeto; & estável (em período de aumento das \\
•Falta de confiança no fornecedor; & vendas); \\
•Desejo de manter uma força de trabalho & •Desejo de manter uma política de múltiplo \\
estável (em período de declínio das & fornecimento; \\
vendas). & •Considerações de suprimento e estoque; \\
& •Considerações de controle gerencial \\
indireto.
\end{tabular}

Figura 2 Aspectos analisados a favor do comprar e do fazer

Fonte: Dobler \& Burt (1996) 
Quinn \& Hilmer (1994) propõem um modelo baseado na vantagem competitiva potencial da atividade e no grau de vulnerabilidade estratégica das atividades, conforme Figura 3:

- Alto grau de vulnerabilidade estratégica e alta vantagem competitiva potencial devem ser realizadas internamente;

- Baixo grau de vulnerabilidade estratégica e baixa vantagem competitiva potencial devem ser terceirizadas;

- Médio grau de vulnerabilidade estratégica e média vantagem competitiva potencial devem ser estudadas e tratadas em condições especiais, por meio de acordos ou empreendimentos.

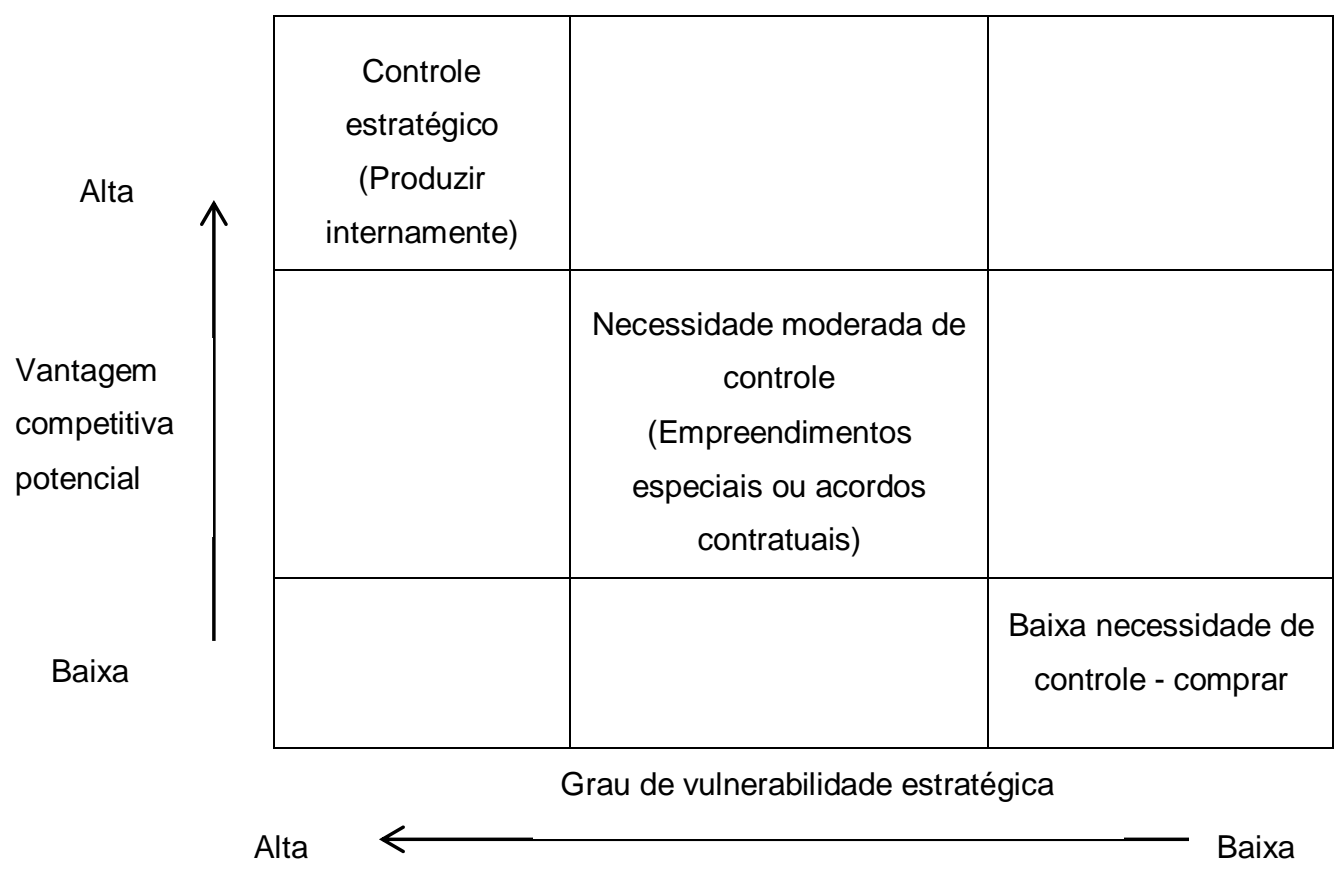

Figura 3 Classificação das atividades de uma empresa

Fonte: Quinn \& Hilmer (1994)

\section{4.}

\section{Estratégia de Compras}

A importância da área de suprimento transformou a atividade de compras em uma função estratégica (DUBOIS, 2003). Analisando a literatura da função compras, verifica-se que as expressões "compras estratégicas" e "estratégia de compras" são frequentemente consideradas como tendo o mesmo significado (ELLRAM \& CARR, 1994). Nesta seção, a estratégia de compras relaciona as ações específicas que a função compras pode executar para atingir. Por 
exemplo, um grupo de gestores pode decidir estabelecer um relacionamento de longo prazo com seus fornecedores-chave como uma estratégia de compras. O conceito de compra estratégica, no entanto, se refere ao processo de estabelecer metas, estabelecendo estratégias, analisando 0 ambiente, implementando e controlando estratégias (CARR \& SMELTZER, 1997). O presente estudo aborda somente a estratégia de compras.

As contribuições da atividade de compras para o desenvolvimento estratégico de uma companhia podem ser resumidas em dois papéis estratégicos: racionalização de custos e desenvolvimento.

De acordo com Dubois (2003), o papel do desenvolvimento consiste na contribuição da função compras ao desenvolvimento técnico da firma, organizando e gerindo os relacionamentos com os fornecedores. Já em relação à racionalização de custos, pode-se subdividir em três principais tipos de papel:

1. Identificação do que precisa ser comprado;

2. Racionalização das atividades logísticas;

3. Racionalização de rotinas administrativas.

Segundo Kraljic (1983), a necessidade de uma empresa estabelecer uma estratégia de compras depende de dois aspectos:

- Importância das compras, do ponto de vista do valor agregado ao produto e custo total e o seu impacto na rentabilidade;

- Complexidade do mercado medida pela escassez de suprimentos, ritmo da substituição de materiais e tecnologias, barreiras de entrada, custo ou complexidade da logística e condições do monopólio ou oligopólio.

A abordagem adotada para compra de produtos e serviços pode ser diferente, em função da natureza do produto, do tipo de produção e da aplicação principal do material (LYSONS \& FARRINGTON, 2006).

Kraljic (1983) considera que cada uma das categorias de itens identificada em seu portfólio necessita de uma abordagem específica, cuja complexidade é proporcional às implicações estratégicas. Referente aos itens críticos, a empresa necessita de grande suporte técnico na tomada de decisões, tais como análise de mercado; análise de risco; simulações e modelos de otimização; análise de preços e outros tipos de análise do ponto de vista microeconômico. Já para os itens não críticos, na maior parte das vezes, uma análise simples de mercado, políticas corporativas de decisão e modelos de otimização de estoque são adequados. 
Para Porter (1986), a estratégia de compra tem por objetivo encontrar mecanismos para compensar ou superar as fontes de poder dos fornecedores. Na Figura 4, Porter (1986) identifica tais fontes e propõe estratégias de compra para confrontá-las:

\begin{tabular}{|c|c|}
\hline Fonte de poder do fornecedor & Estratégia de compras \\
\hline $\begin{array}{l}\text { Concentração de compras com } 0 \\
\text { fornecedor }\end{array}$ & $\begin{array}{l}\text { Dispersão de compras, impedindo } \\
\text { pulverização, ao ponto de deixar de ser } \\
\text { significativa a parcela de venda para o } \\
\text { fornecedor }\end{array}$ \\
\hline $\begin{array}{l}\text { Não dependência do fornecedor com } \\
\text { relação ao cliente para uma fração } \\
\text { substancial das vendas }\end{array}$ & $\begin{array}{l}\text { Promoção de fontes alternativas } \\
\text { qualificadas, através de financiamento de } \\
\text { contratos de desenvolvimento de novos } \\
\text { fornecedores }\end{array}$ \\
\hline Produto diferenciado ou único & $\begin{array}{l}\text { Padronização de especificações nas } \\
\text { indústrias das quais adquire seus } \\
\text { insumos }\end{array}$ \\
\hline $\begin{array}{l}\text { Ausência de ameaça real de integração } \\
\text { "para trás" por parte do comprador }\end{array}$ & $\begin{array}{l}\text { Criação de uma ameaça de integração } \\
\text { "para trás" através de declarações, } \\
\text { estudos } \\
\text { de viabilidade }\end{array}$ \\
\hline $\begin{array}{l}\text { Custos de mudança enfrentados pelo } \\
\text { cliente }\end{array}$ & $\begin{array}{l}\text { Ausência de custos de mudanças, tais } \\
\text { como: desenvolvimento de modelos } \\
\text { personalizado ou com aplicação } \\
\text { específica; produtos com necessidade de } \\
\text { treinamento especializado para os } \\
\text { empregados }\end{array}$ \\
\hline $\begin{array}{l}\text { Domínio de altos custos de informação, } \\
\text { compra e negociação por parte do } \\
\text { comprador }\end{array}$ & Uso de integração parcial \\
\hline
\end{tabular}

Figura 4 Estratégias de compra em função da fonte de poder do fornecedor Fonte: Porter (1986)

Para Pazirandeh \& Normann (2014), as organizações se inter-relacionam (e.g. com fornecedores) para obterem fontes necessárias e, então, se tornarem interdependentes. No entanto, essa interdependência não é uniformemente distribuída e alguns atores na cadeia de suprimento se tornam mais influentes. A 
parte enfraquecida, então, se defronta com alguns obstáculos em gerir através de suas estratégias. Em uma situação onde o comprador é altamente dependente de sua base de fornecedores, as estratégias de compras são executadas em resposta às dificuldades encontradas. A ideia que as empresas são restringidas e influenciadas por fatores externos ao seu ambiente é largamente aceita na teoria. Porém, o suporte empírico para tais previsões é limitado.

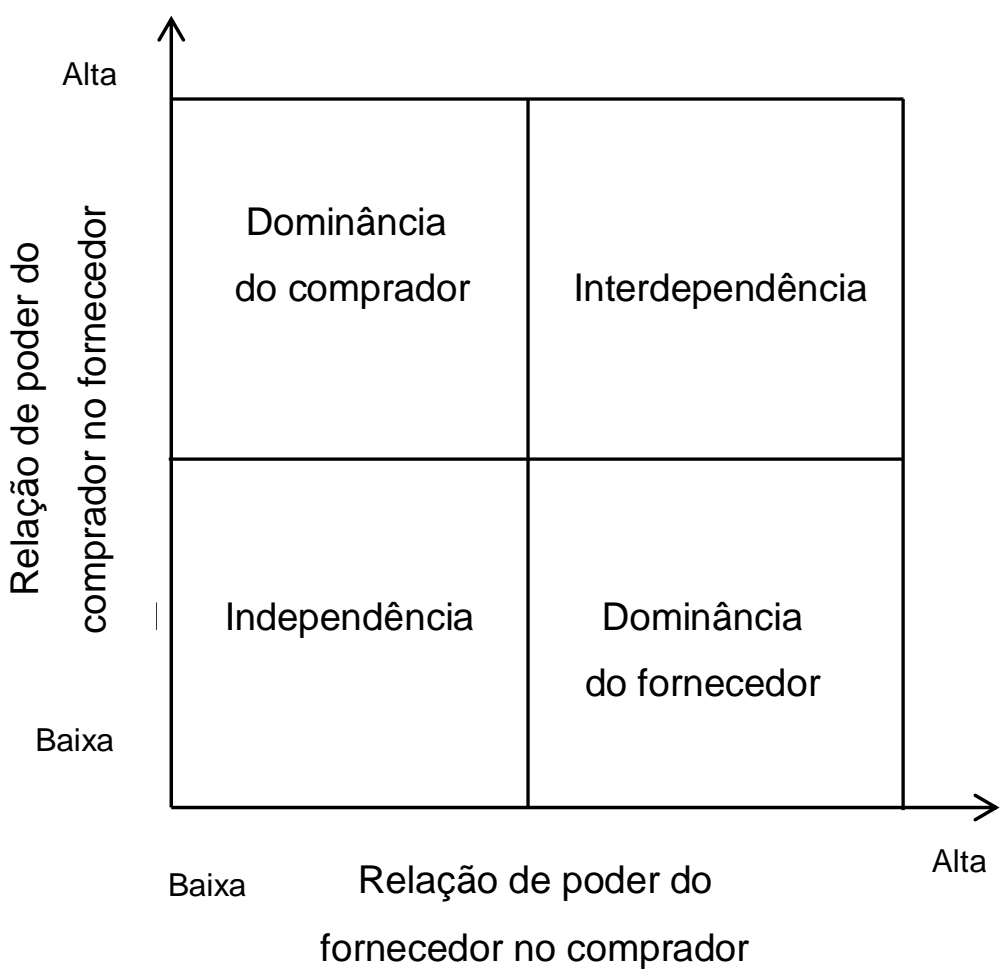

Figura 5 Estrutura de poder comprador-fornecedor

Fonte: Pazirandeh \& Normann (2014).

Para entender o poder de compra, os fatores que elevam o de baixa e o de alta devem ser identificados. Ainda segundo Pazirandeh \& Normann (2014), a inter-relação entre a estratégia de compras e o poder de compra é um fenômeno dinâmico, que pode ser bem estudado no contexto da vida real. Em geral, as estratégias de compras, planejadas ou não, impactam nas fontes de poder. Em alguns casos, a combinação de mudanças nas fontes de poder contribuem para um poder de compra modificado. Uma alta dependência dos fornecedores, no entanto, torna difícil para os compradores mudarem seus poderes de compra para "independência" ou "dominância do comprador". 
Carr \& Smeltzer (1997) realizaram um grande estudo sobre a história da estratégia de compras. Nesse estudo, consideraram que a função compras vem se tornando uma função com importante papel na estratégia das empresas e que existem três tipos de estratégia de compras:

- Estratégica específica empregada pela própria função compras;

- Papel de compras no suporte de estratégias de outras funções e da firma como um todo;

- Utilização de compras como uma função estratégica da empresa.

No mesmo estudo, Carr \& Smeltzer (1997) analisam três questões básicas sobre 0 assunto.

As questões e opções estratégicas fundamentais que a função compras enfrenta são: a decisão de fazer ou comprar, a tecnologia do fornecedor, o tipo desejado de relacionamento com o fornecedor, fatores de mercado externos; e como compras pode corroborar a estratégia competitiva da empresa.

O segundo ponto é focado na possível integração da função compras dentro da estratégia corporativa. A revisão claramente indica que a estratégia de compras deve ser parte da estratégia global da empresa. O movimento em direção a fornecimentos globais, rápidas mudanças em tecnologia e o aumento da competitividade requerem que compras assuma mais responsabilidade no planejamento e implantação de estratégias para suportar a estratégia corporativa.

No último aspecto analisado, a função compras representa um papel quando é incluída no planejamento e implementação estratégicos no mesmo nível de outras funções. Isso ocorre quando a importância de compras é reconhecida, aceita e operada pela alta gestão da empresa. Compras precisa passar por estágios para alcançar tal posto naturalmente e, então, genuinamente contribuir para a estratégia corporativa. Então, compras tende a evoluir e crescer numa postura estratégica dentro da empresa. Essa evolução requer da função compras desenvolver novas habilidades e ser reconhecida como um contribuinte chave para a estratégia corporativa pela alta diretoria. Como pré-requisito dessa evolução, torna-se evidente que a postura dos gestores de compras e da alta gestão necessita de mudança para, então, compras poder desempenhar um papel estratégico . Mudar a visão da gestão costuma ser um lento processo na maioria das organizações - adicionalmente, muitas operações de compras ainda não têm as habilidades e entendimentos requeridos para contribuir efetivamente com a estratégia corporativa. 


\section{5.}

\section{Análise de Portfólio de Kraljic}

Os modelos de portfólio são amplamente vistos na gestão de negócios em vários níveis de agregação e são utilizados com diferentes combinações de fatores ou componentes do portfólio, em razão do objetivo e da situação na qual a empresa se encontra. Esse tipo de modelo estabelece uma rotina para o julgamento e a decisão de alocação de recursos, buscando uma combinação ótima que atenda aos interesses do negócio em longo prazo (Olsen \& Ellram, 1997).

O modelo de Kraljic (1983) é considerado como uma referência no desenvolvimento da teoria da gestão de suprimento e introduziu o primeiro método de portfólio de compras. Apesar das limitações, outros pesquisadores utilizaram como referência 0 modelo de Kraljic, modificando-o e complementando-o. A partir de Kraljic, surgiram outros autores que incluíram variáveis e apresentaram modificações justificadas pela necessidade de contemplar questões importantes para a atual gestão de suprimentos.

Kraljic (1983) classifica em seu modelo os produtos comprados de acordo com seu impacto sobre a lucratividade da empresa (importância) e o risco de fornecimento (complexidade do mercado fornecedor). Dividido em quatro passos, o método cria uma estrutura de categorização dos itens comprados e do mercado fornecedor, conforme ilustrado na Figura 5. Diferentes estratégias de suprimentos são sugeridas por meio destas categorizações.

Kraljic (1983) questiona as estruturas de gestão de suprimentos e a capacidade dos altos executivos e gestores de suprimentos das empresas quanto às suas habilidades em lidar com eventos como:

- Interrupções abruptas nos seus fornecimentos de insumos;

- Mudanças econômicas e novas oportunidades trazidas por novas tecnologias;

- Manutenção de lucros em mercados globais e, ao mesmo tempo, sujeitos a fortes pressões protecionistas.

Segundo Kraljic (1983), deve-se chamar a atenção para a necessidade de um posicionamento autocrítico por parte das empresas quanto à compreensão $\mathrm{e}$ enfretamento dos riscos aos seus negócios decorrentes do aumento irreversível da complexidade na busca por fontes de recursos em nível global. Assim, Kraljic (1983) alerta que o processo de compras deve se tornar um processo de gestão dos suprimentos. 
O autor define que o diagnóstico da situação da empresa quanto á sua necessidade por estratégias de suprimentos pode ser feito utilizando-se dois fatores:

i) A importância estratégica da compra em termos de valor agregado por tipo de produto; de porcentagem de custos de matéria-prima; de seu impacto na lucratividade etc.

ii) A complexidade do mercado supridor ponderada pela escassez de suprimentos; velocidade de inovação de tecnologias e/ou substituição de materiais; barreiras de entradas; custo ou complexidade logística; existência ou condições para existência de monopólios ou oligopólios.

Segundo o autor, uma adequada avaliação da empresa com base nessas duas variáveis permite a determinação do tipo de estratégia de suprimento que a companhia precisa, considerando a potencialização das suas forças frente aos fornecedores importantes e a redução de riscos a níveis aceitáveis.

O autor apresenta uma metodologia que possibilita a identificação de fraquezas e oportunidades na gestão de suprimentos das empresas e a elaboração de estratégias e planos de ação alinhados com os objetivos e riscos do negócio.

Assim, Kraljic (1983) propõe uma matriz que consiste de quatro quadrantes, cada um representando um tipo de estratégia a ser desenvolvida pela empresa, demonstrados na Figura 6:

- Quadrante I (Baixa complexidade do mercado supridor e Baixa importância da compra): Estratégia baseada no gerenciamento da compra, caracterizada pela aquisição de itens não críticos, num mercado supridor abundante;

- Quadrante II (Baixa complexidade do mercado supridor e Alta importância da compra): Estratégia baseada no gerenciamento de materiais, caracterizada pela aquisição de itens alavancados (equipamentos e sistemas), num mercado supridor abundante;

- Quadrante III (Alta complexidade do mercado supridor e Baixa importância da compra): Estratégia baseada no gerenciamento de fornecedores, caracterizada pela aquisição de itens "gargalos", num mercado supridor escasso ("Taylor made");

- Quadrante IV (Alta complexidade do mercado supridor e Alta importância da compra): Estratégia baseada no gerenciamento do suprimento, caracterizada pela aquisição de itens estratégicos, num mercado supridor caracteristicamente escasso ("Taylor made"). 


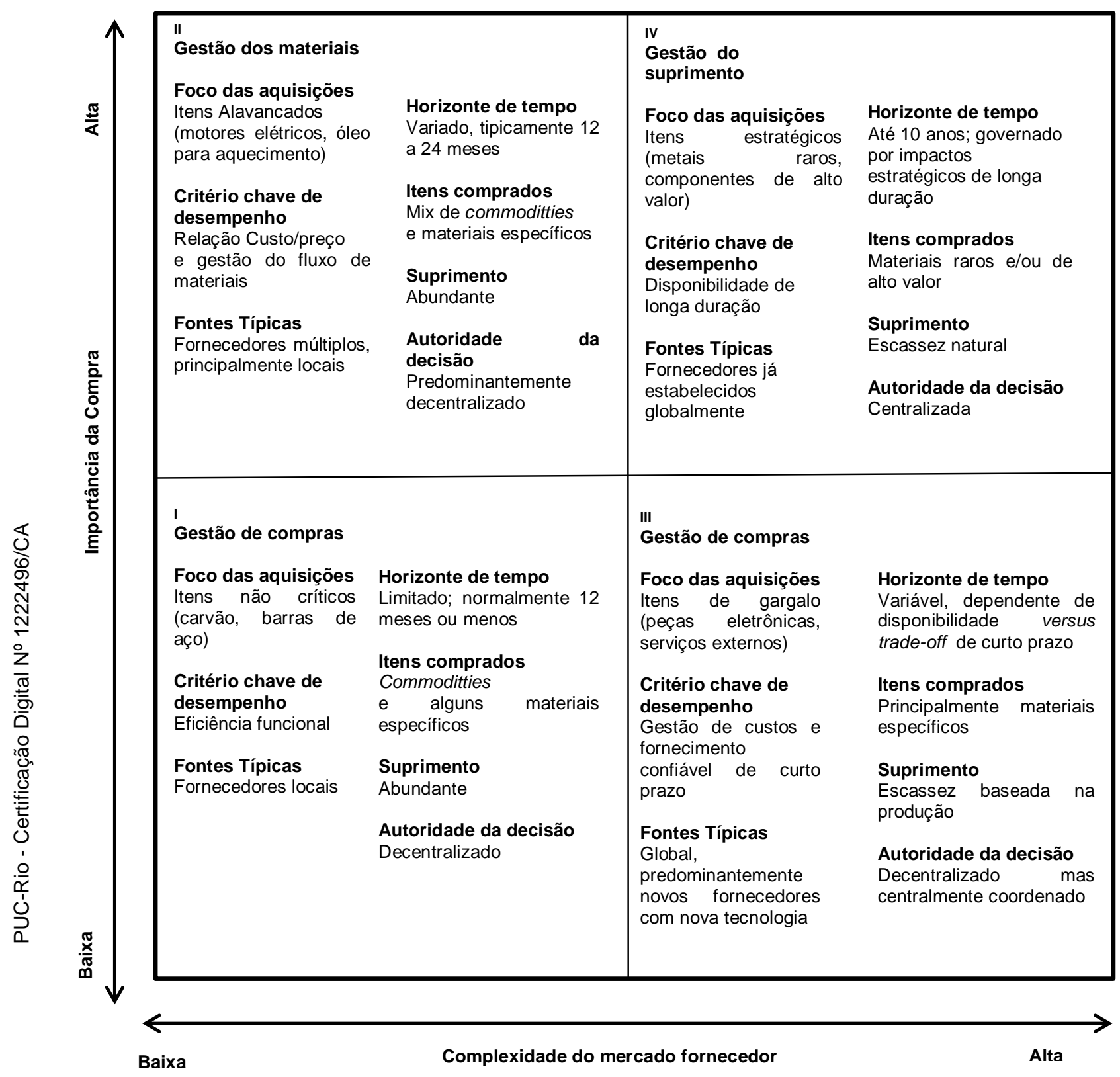

Figura 6 Estágios de Sofisticação de Compras

Fonte: Kraljic (1983).

Para identificar quais estratégias de suprimento devem ser desenvolvidas pela empresa, o autor propõe uma abordagem baseada em quatro fases:

Fase 1 - Classificação das Aquisições: Classificação de todas as aquisições em termos de impacto nos lucros e riscos de suprimento. Para isso, Kraljic (1983) cria uma matriz com os seguintes eixos: 
- Importância das Compras: resultante do percentual dos itens comprados no custo total e seus impactos na lucratividade. Esse eixo indica o potencial da compra para aumentar a rentabilidade da empresa (eixo vertical).

- Complexidade do Mercado Fornecedor: composto por escassez de suprimentos, avanço tecnológico, substituição de materiais e poder de compra. Esse eixo contém as vulnerabilidades da empresa compradora frente ao mercado fornecedor do produto comprado.

Assim, as aquisições são inseridas numa matriz em: Itens Estratégicos; Itens "Gargalos" ou Críticos; Itens de Alavancagem; Itens Não-Críticos; conforme Figura 7.

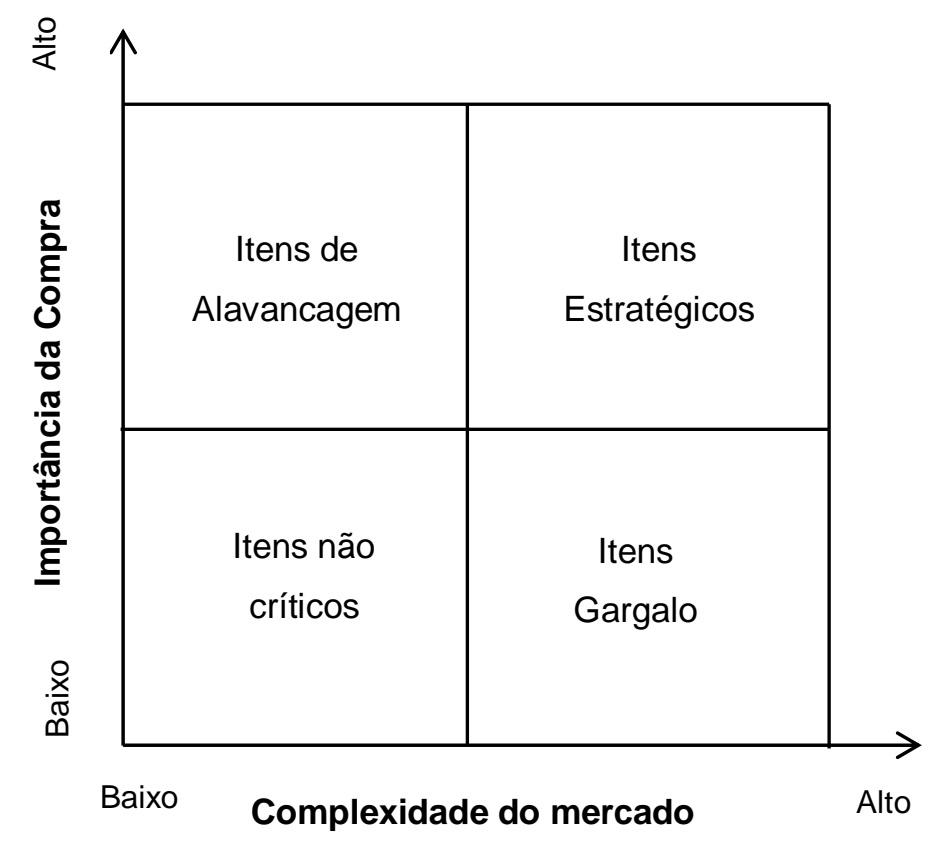

Figura 7 Classificação dos itens

Fonte: Kraljic (1983)

Para exemplificar como os itens podem ser classificados dentro de uma empresa, Baily et al. (2000) sugerem algumas compras que ajudam a explicar os significados das categorias e a ideia de posicionamento. O motor de avião para uma empresa da indústria aeronáutica pode ser atribuído como um elemento estratégico, já que, em princípio, é um item com alta importância de compra e com alta complexidade do mercado fornecedor. O papel para uma gráfica pode ser avaliado como baixa complexidade de mercado fornecedor, mas alta importância da compra que o coloca na categoria de alavancagem. No 
quadrante Gargalo, devem ser posicionados os produtos de baixa importância da compra, porém com alta complexidade do mercado fornecedor. Uma consultoria é um exemplo de item gargalo. Finalmente, podem ser classificados como itens não críticos os materiais de escritório, que claramente são vistos como de baixa importância da compra e de baixa complexidade do mercado fornecedor.

Dado o posicionamento dos itens de compras na Figura 9, é necessário analisar algumas das atividades principais, informações requeridas e níveis de decisão de cada uma das categorias que estão listadas na Figura 8.

\begin{tabular}{|c|c|c|c|}
\hline $\begin{array}{l}\text { Foco de } \\
\text { Compras }\end{array}$ & Atividades Principais & Informação Requerida & $\begin{array}{l}\text { Nível de } \\
\text { Decisão }\end{array}$ \\
\hline $\begin{array}{l}\text { Itens } \\
\text { Estratégicos }\end{array}$ & $\begin{array}{l}\text { - Previsão de demanda acurada } \\
\text { - Estudo detalhado do mercado fornecedor } \\
\text { - Desenvolvimento de relacionamento com } \\
\text { - fornecedores de longo prazo } \\
\text { - Decisões de produzir ou comprar } \\
\text { - Análise de Risco } \\
\text { - Plano de Contingência } \\
\text { - Controle logístico (transporte e } \\
\text { armazenagem) }\end{array}$ & $\begin{array}{l}\text { - Dados detalhados do } \\
\text { mercado fornecedor } \\
\text { - Informações de } \\
\text { fornecimento e demanda } \\
\text { no curto e longo prazo } \\
\text { - Inteligência competitiva } \\
\text { - Curvas de custos } \\
\text { industriais }\end{array}$ & $\begin{array}{l}\text { Top (cúpula da } \\
\text { empresa) }\end{array}$ \\
\hline Itens Gargalo & $\begin{array}{l}\text { - Assegurar volume } \\
\text { - Controle dos fornecedores } \\
\text { - Estoques de segurança } \\
\text { - Planos de substituição }\end{array}$ & $\begin{array}{l}\text { - Previsões de } \\
\text { demanda/fornecimento em } \\
\text { médio prazo } \\
\text { - Dados detalhados do } \\
\text { mercado fornecedor }\end{array}$ & $\begin{array}{l}\text { Alto nível } \\
\text { (chefes dos } \\
\text { departamentos) }\end{array}$ \\
\hline $\begin{array}{l}\text { Itens } \\
\text { Alavancagem }\end{array}$ & $\begin{array}{l}\text { - Exploração do poder de compra } \\
\text { - Seleção de fornecedor } \\
\text { - Substituição do fornecedor } \\
\text { - Estratégias/negociações de preços alvos } \\
\text { - Otimização do volume de pedidos }\end{array}$ & $\begin{array}{l}\text { - Informações adequadas } \\
\text { do mercado fornecedor } \\
\text { - Planejamento da demanda } \\
\text { - Dados precisos do } \\
\text { fornecedor }\end{array}$ & $\begin{array}{l}\text { Nível médio } \\
\text { (comprador } \\
\text { chefe) }\end{array}$ \\
\hline $\begin{array}{l}\text { Itens Não- } \\
\text { Críticos }\end{array}$ & $\begin{array}{l}\text { - Padronização de produtos } \\
\text { - Otimização/monitoramento de volume dos } \\
\text { pedidos } \\
\text { - Processamento eficiente das compras }\end{array}$ & $\begin{array}{l}\text { - Boa visão geral do } \\
\text { mercado fornecedor } \\
\text { - Previsões de demanda de } \\
\text { curto prazo }\end{array}$ & $\begin{array}{l}\text { Nível baixo } \\
\text { (compradores) }\end{array}$ \\
\hline
\end{tabular}

\section{Figura 8 Posicionamento dos itens de compra}

Fonte: Kraljic (1983)

Fase 2 - Analise de Mercado: Nesta fase a empresa pondera o poder de barganha dos seus fornecedores contra sua força como consumidor (Figura 9); 


\begin{tabular}{|c|c|c|}
\hline & Força do fornecedor & Força da Companhia \\
\hline 1 & $\begin{array}{l}\text { Tamanho do mercado versus capacidade do } \\
\text { fornecedor }\end{array}$ & $\begin{array}{l}\text { Volume de compras versus capacidade das } \\
\text { unidades principais }\end{array}$ \\
\hline 2 & $\begin{array}{l}\text { Crescimento do mercado versus crescimento } \\
\text { da capacidade }\end{array}$ & $\begin{array}{l}\text { Crescimento da demanda versus crescimento da } \\
\text { capacidade }\end{array}$ \\
\hline 3 & $\begin{array}{l}\text { Utilização da capacidade produtiva ou risco } \\
\text { de gargalo }\end{array}$ & Capacidade de utilização das principais unidades \\
\hline 4 & Estrutura competitiva & Market share frente a competições importantes \\
\hline 5 & ROI e/ou ROC & Lucratividade dos principais produtos finais \\
\hline 6 & Estrutura de custo e preço & Estrutura de custo de preço \\
\hline 7 & $\begin{array}{l}\text { Ponto de equilibrio (break-even) } \\
\text { ExclusivIdade de produto e estabIIIdade }\end{array}$ & Custo da não-entrega \\
\hline 8 & tecnológica & Capacidade de produção própria \\
\hline 9 & $\begin{array}{l}\text { Barreira de entrada (capital e requisitos de } \\
\text { know how) }\end{array}$ & $\begin{array}{l}\text { Custo inicial para novas fontes versus custo para } \\
\text { produção própria }\end{array}$ \\
\hline 10 & Situação logística do fornecedor & Logística da companhia \\
\hline
\end{tabular}

Figura 9 Fatores para Avaliação da Força do Comprador e do Fornecedor

Fonte Kraljic (1983)

Segundo Carvalho (2010), a empresa precisa analisar o mercado para avaliar a disponibilidade (quantidade e qualidade) de materiais estratégicos e 0 nível da "força" relativa dos fornecedores. Depois, deverá analisar as suas necessidades e linhas de abastecimento para verificar se pode ser abastecida nos termos em que deseja. Faz-se fundamental que a empresa consiga identificar os pontos fortes e as limitações do fornecedor, assim como entender o impacto que eles podem ter na companhia e no equilíbrio do poder entre comprador e fornecedor.

A companhia reanalisa sistematicamente o mercado de suprimento, estimando a necessidade de materiais estratégicos em termos de qualidade e quantidade, assim como a força relativa dos vendedores existentes para medir sua capacidade de alcançar as condições de suprimento que ela almeja (KRALJIC, 1983).

Fase 3 - Posicionamento Estratégico: Nesta fase, a empresa posiciona as aquisições identificadas como estratégicas em uma matriz forças da empresa versus forças do mercado supridor, divida em nove quadrantes (baixo, médio, alto para cada eixo) permitindo identificar áreas de vulnerabilidades ou oportunidades, avaliar riscos de suprimentos e estabelecer estratégias básicas 
para atacar esses riscos. Em termos de estratégias, os agrupamentos dos quadrantes definem três tipos de abordagem: Agressiva, Diversificada e Balanceada.

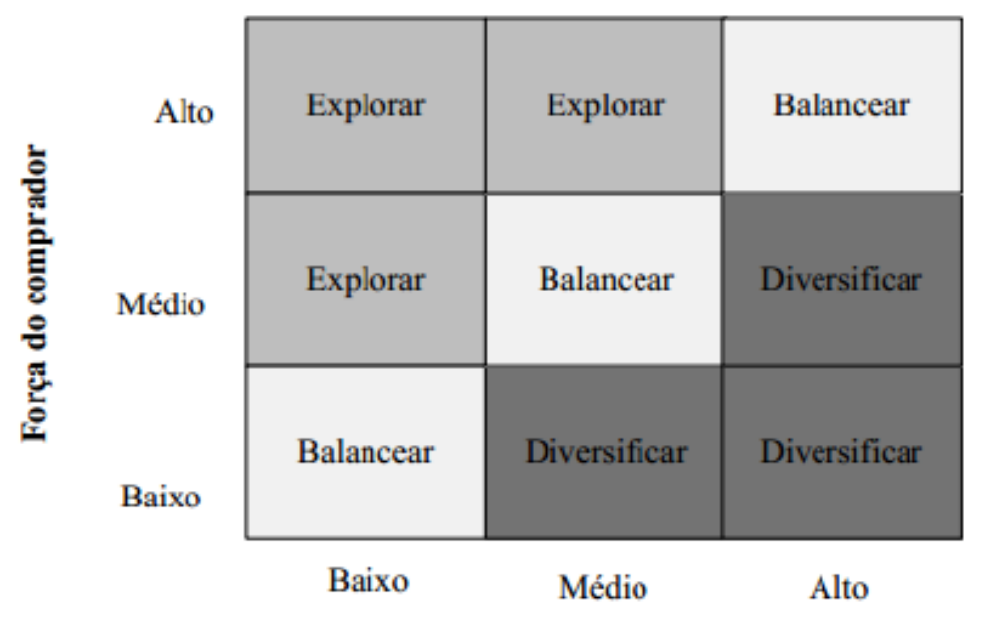

Força do mercado de fornecimento

Figura 10 Matriz de portfolio de compras

Fonte: Kraljic (1983)

I. Agressiva (Explorar): É uma estratégia aplicada a artigos sobre os quais o comprador tem um papel dominante no mercado. Tendo em vista que a "força" do fornecedor é média ou baixa, o risco de abastecimento, também, será médio/baixo, o que proporciona à empresa uma oportunidade para pressionar os seus fornecedores e conseguir preços mais favoráveis.

II. Diversificada: Para itens onde o papel da companhia é secundário e os fornecedores são "fortes", a empresa deve permanecer numa postura defensiva e começar a procurar por materiais substitutos ou por novos fornecedores (diversificar).

III. Balanceada: Para itens de suprimento que não há riscos nem benefícios muito visíveis, uma postura defensiva seria ultraconservadora e cara.

Fase 4 - Planos de Ação: Cada uma das três abordagens estratégicas tem implicações distintas com os elementos individuais da estratégia de compras, tais como volume, preço, seleção do fornecedor, etc. (Figura 11). 
Para cada um dos três tipos de estratégia definidas na Fase 3 são estabelecidos planos de ação específicos e sistematicamente documentados, que especificam o tempo e o critério para futuras ações.

\begin{tabular}{|c|c|c|c|}
\hline $\begin{array}{l}\text { Itens da política de } \\
\text { suprimentos }\end{array}$ & $\begin{array}{l}\text { Posição estratégica - } \\
\text { "explorar" }\end{array}$ & $\begin{array}{l}\text { Posiçâo estratégica - } \\
\text { "balancear" }\end{array}$ & $\begin{array}{l}\text { Posiçaio estratégica - } \\
\text { "diversificar" } \\
\end{array}$ \\
\hline Volume & $\begin{array}{l}\text { Distribuir entre os } \\
\text { fornecedores }\end{array}$ & $\begin{array}{l}\text { Manter ou alterar } \\
\text { cuidadosamente entre os } \\
\text { fornecedores }\end{array}$ & Centralizar \\
\hline Preço & Pressionar por reduções & $\begin{array}{l}\text { Negociar em cima de } \\
\text { oportunidades }\end{array}$ & Mantê-lo \\
\hline Cobertura contratual & Comprar sob demanda & $\begin{array}{l}\text { Balancear entre contratos } \\
\text { e compra sob demanda }\end{array}$ & $\begin{array}{l}\text { Garantir o fornecimento } \\
\text { através de contratos }\end{array}$ \\
\hline Novos fornecedores & Manter contato & Selecionar fornecedores & Procurar intensivamente \\
\hline Estoques & Manter baixo & $\begin{array}{l}\text { Usar estoques como } \\
\text { pulmão (buffer) }\end{array}$ & Estoque intensivo \\
\hline Produção própria & Reduzir ou não produzir & Decidir seletivamente & Produzir \\
\hline Substituição & Manter contato & $\begin{array}{l}\text { Procurar boas } \\
\text { oportunidades }\end{array}$ & Procurar intensivamente \\
\hline Logística & Minimizar custos & Otimizar seletivamente & $\begin{array}{l}\text { Estoques de segurança } \\
\text { suficientes }\end{array}$ \\
\hline
\end{tabular}

\section{Figura 11 Implicações das Posições Estratégicas Escolhidas}

Fonte: Kraljic, 1983.

Após a análise de Kraljic (1983), autores usaram seu portfólio para o desenvolvimento de modelos similares, com alto grau de semelhança a matriz originalmente proposta. Alguns destes métodos na literatura são os de Olsen \& Ellram (1997) e Bensaou (1999). Ademais, existem diversas aplicações do modelo de Kraljic, como o envolvimento dos fornecedores no desenvolvimento de produtos, a seleção de fornecedores, (HANDFIELD et al., 2000) e especificação de processos (NELORE \& SODERQUIST, 2000).

A principal crítica ao modelo proposto por Kraljic é que, ao reduzir as questões a duas dimensões, a representação matricial não captura aspectos relevantes das transações comerciais atuais, assim como os negócios realizados através de redes de empresas (DUBOIS \& PEDERSEN, 2002) e o conceito de vantagem competitiva e sustentável nos relacionamentos entre as empresas (PAGELLI \& WU, 2009).

Ademais, outra crítica importante ao modelo é que Kraljic (1983) não analisa como atribuir os pesos para os eixos. Assim, para classificar suas compras no portfólio de Kraljic (1983), as empresas precisam atribuir pesos aos critérios e fatores, baseados na percepção dos gestores e nas informações da companhia (OLSEN \& ELLRAM, 1997). 


\section{3 \\ Visão geral do Transporte Marítimo (Shipping)}

Neste capítulo, é feita uma contextualização do estudo de caso quanto ao tipo de contratação, apresentando os conceitos que envolvem o transporte marítimo e o afretamento de navios.

\section{1. Transporte Marítimo}

A economia mundial é fortemente dependente do transporte marítimo, que é provavelmente o modal de transporte mais importante nos dias de hoje. Por ano, mais de sete bilhões de toneladas são carregadas por navios e esse número aumenta a cada ano. A construção de um navio envolve grande investimento de capital (usualmente milhões de dólares, dezenas de milhões para os maiores) e um grande contrato de longo prazo para um operador de navio pode levar muitos anos e requerer um aumento considerável no tamanho da frota. O planejamento adequado da frota e de suas operações tem o potencial de melhorar seu desempenho econômico e reduzir os custos de navegação (FAGERHOLT et al., 2010).

O transporte marítimo exerce um papel chave no mercado de petróleo e seus derivados, incluindo produtores, negociantes (traders), refinadores, distribuidores, assim como os armadores (owners, donos dos navios) e companhias de transporte marítimo de petróleo (oil shipping companies), operadores e afretadores de navios tanque com o propósito de transporte e toda a logística, incluindo a distribuição dessas commodities de energia ao redor do mundo. Qualquer oscilação cíclica, volatilidade ou flutuações no petróleo e/ou em seus derivados pode afetar o frete ou o aluguel do navio para transportar esses produtos do local de produção ao de consumo (ALIZADEH, et al. 2015).

A principal vantagem do modal marítimo é a sua capacidade individual, maior que qualquer outro modal de transportar em grandes quantidades quaisquer cargas (sólidas ou líquidas; embaladas, unitizadas ou a granel), o que proporciona elevada economia de escala. Isso se deve ao fato de a indústria 
naval ter desenvolvido navios especializados para o transporte de cada tipo de carga, otimizando sua operação na cadeia logística. Além disso, o modal apresenta alta eficiência energética (SARACENI, 2006).

Considerando-se as frotas dos diversos tipos de navios cargueiros, podese dizer que o modal apresenta não somente inigualável capacidade individual de transporte, como também, no agregado de suas diversas frotas, a maior capacidade total entre todos os modais existentes. Por outro lado, o transporte marítimo precisa da existência de portos e terminais altamente dispendiosos, o que exige investimentos prévios de alto valor para as localidades envolvidas no transporte. (SARACENI, 2006).

O perfil da indústria do petróleo, no qual a produção encontra-se geralmente muito distante dos centros de consumo, muitas vezes em outro continente, restringe a possibilidade de transporte à utilização de dois modais capazes de interligar continentes: marítimo e aéreo. Por sua vez, os grandes volumes movimentados, o valor agregado relativamente baixo do óleo cru e a utilização de aeronaves capazes de transportá-lo a granel ser quase que exclusivamente de forças armadas, obrigam, por necessidade e economicidade, o uso comercial de um único modal: o marítimo (SARACENI, 2006).

As operações de navio são usualmente classificadas em três tipos (FAGERHOLT et al., 2010):

- Liners (chamadas regulares) - rotas preestabelecidas e atendidas com regularidade por navios de um armador ou grupo de armadores. Os serviços regulares são atendidos tanto por conferências (agrupamentos) de fretes como por outsiders (navios de armadores sem vínculos com as conferências). (SARACENI, 2010). Funcionam como ônibus, com itinerários e programações públicas (FAGERHOLT et al., 2010);

- Rotas irregulares (tramps) - denominação aplicável aos navios que operam buscando cargas de oportunidade, fora de rotas regulares. Para Fagerholt et al. (2010), navegação tipo tramp é similar à operação de um táxi, onde o navio vai para onde há cargas disponíveis. Uma companhia de navegação por tramp costuma ter certa quantia de cargas de contrato que podem ser consideradas como obrigatórias. Além disso, a empresa tenta aumentar seu lucro com cargas spot. No transporte de granéis é comum a predominância de navios tramps (SARACENI, 2006);

- Afretamento (chartering) - o afretamento de uma embarcação é recomendado quando a quantidade de carga a ser transportada é suficiente para ocupá-la totalmente ou em grande parte. $\mathrm{Na}$ indústria de petróleo e seus 
derivados, o afretamento de navios é o tipo mais corrente de utilização do modal (SARACENI, 2006). Fagerholt et al. (2010) acrescentam que, nesta categoria, denominada Navegação Industrial, o transportador ou o dono da carga também controla a frota de navios.

Entre os anos de 2002 e 2008, a indústria de transporte marítimo experimentou um crescimento sem precedente nas taxas de frete e de aluguel de navios, resultando em altos resultados financeiros para os donos de navios. Isso levou a um número crescente de companhias de navegação lançando suas ações nas grandes bolsas de valores do mundo. Independente do setor em que operam, navios-tanques ou graneleiros, os donos de navios acreditam que a concentração das propriedades dos navios proporciona a eles flexibilidade, o que é necessário em um ambiente altamente volátil (TSIONAS, 2012).

Segundo Saraceni (2006), os navios podem ser classificados quanto ao tipo de carga transportada. No caso da indústria do petróleo, os navios utilizados são conhecidos como navios-tanque (granel líquido), projetados para o transporte de cargas líquidas a granel de acordo com as normas internacionais de segurança. A carga é bombeada de terra para dentro dos tanques do navio através de mangotes no carregamento e, bombeada pelo navio, em sentido inverso, na descarga. Os navios-tanques podem ser:

- Petroleiros - navios para o transporte de óleo cru e seus derivados. Dependendo da carga a ser transportada, podem ter seus tanques revestidos com materiais especiais (epóxi, silicato de zinco etc.) e sistemas de aquecimento (serpentinas ou trocadores de calor) (SARACENI, 2006).

- Gaseiros - navios capazes de transportar gases em seu estado liquefeito, por pressurização, refrigeração ou pela combinação de ambos os processos. Podem transportar GLP (gás liquefeito de petróleo), GNL (gás natural liquefeito) ou gases petroquímicos (eteno, butadieno, propeno, amônia anidra etc.), dependendo de suas características e capacidades (SARACENI, 2006).

- Navios Químicos - navios geralmente compostos de muitos tanques de pequenas dimensões individuais, chamados de parcel-tankers. Tal característica permite o transporte de muitas cargas diferentes na mesma viagem, otimizando o custo de transporte. Dadas as características especiais dos produtos transportados, esses navios são bastante sofisticados, podendo, por exemplo, ser equipados com tanques de aço inoxidável. Alguns navios químicos são apropriados, também, ao transporte de óleos vegetais a granel (SARACENI, 2006). 
$\mathrm{Na}$ Tabela 1 encontra-se listada a classificação de navios mais utilizada. Originalmente, o termo PANAMAX se refere ao tamanho máximo para passagem pelo Canal do Panamá (que comporta navios com largura máxima de 32,2 metros) e o termo SUEZMAX, ao tamanho para passagem pelo Canal de Suez. No entanto, AFRAMAX não se refere a nenhum local geográfico. O London Tanker Brokers Panel (Painel de Corretores de Navios Petroleiros de Londres) há muitos anos determina a média das taxas de frete do mercado (AFRAAverage Freight Rate Assessment). Essa média levava em conta os fretes de navios até 80.000 TPB, que era, então, o tamanho máximo do AFRA. É importante lembrar que, até meados dos anos 1980, os navios PANAMAX tinham em média até 60.000 TPB e o termo AFRAMAX designava os navios entre 60.000 e 80.000 TPB (SARACENI, 2006).

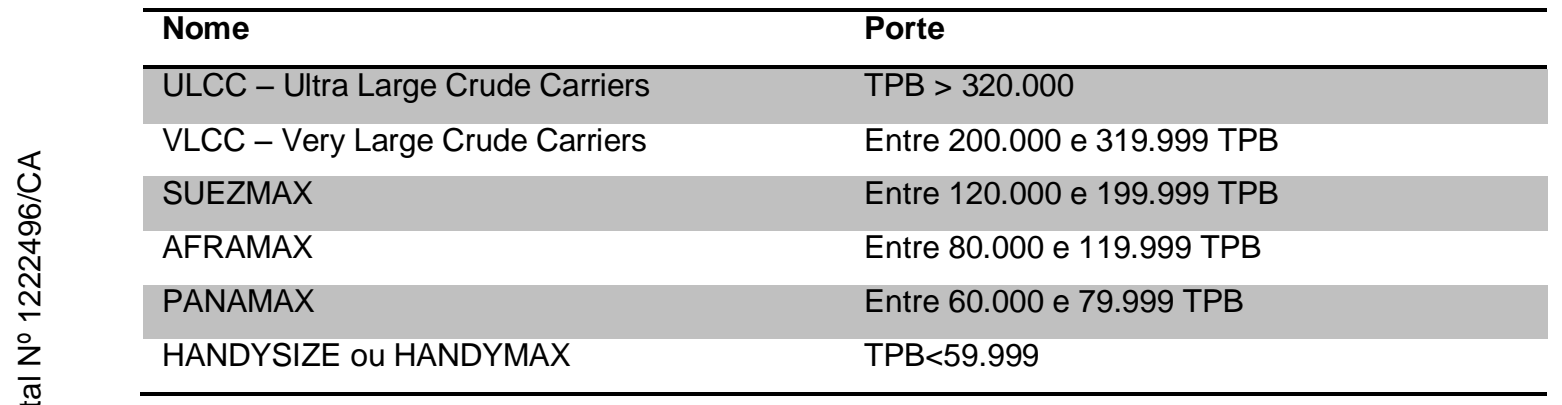

Tabela 1 Classificação dos Navios de petróleo e derivados quanto ao porte Fonte: Saraceni, 2006.

Os navios de derivados claros se enquadram, em relação ao seu porte, nas categorias exibidas na Tabela 2:

\begin{tabular}{ll}
\hline Nome & Porte \\
\hline LR2 - Long Range 2 (AFRAMAX) & Entre 80.000 e 119.999 TPB \\
LR - Long Range 1 (PANAMAX) & Entre 50.000 e 79.999 TPB \\
MR - Mid Range (HANDYSIZE) & Entre 40.000 e 49.999 TPB \\
SR - Short Hand (HANDYSIZE) & TPB<39.999 \\
\hline
\end{tabular}

Tabela 2 Classificação dos navios de derivados claros quanto ao porte

Fonte: Adaptado de Saraceni, 2006. 


\section{2.}

\section{Afretamento}

O processo de alugar um navio com o propósito de carregar cargas por vias aquaviárias é chamado de afretamento. Tal processo envolve a negociação para discutir os termos e condições comerciais do contrato; a elaboração do contrato em si, conhecido como Charter Party, e sua execução; além da fase posterior à celebração do contrato (post/fixture), que envolve os pagamentos de frete/hire e sobre-estadia e a discussão de eventuais sequelas contratuais (claims), tal como a arbitragem referente a alguma disputa entre as partes. Compreende-se, então, que o afretamento tem conotações práticas (a movimentação da carga) e também legais.

Quanto aos participantes do processo, existem três principais atores: o fretador, o afretador e o broker.

O fretador é a parte contratual que cede a embarcação, ou parte dela, mediante o pagamento de aluguel por um período determinado. Em relação à posse do navio, pode ser o armador real do navio (owner, aquele que detém sua propriedade) ou o armador disponente (Disponent owner, aquele que o controla por força de arrendamento ou afretamento) (SARACENI, 2006).

A parte contratual que aluga a embarcação para o transporte de cargas ou de passageiros, pagando para tal fim, frete ou aluguel por período determinado ao fretador é chamada de afretador. $O$ afretador pode ser um time-charterer (afretado por período) ou um voyage-charterer (afretado por viagem). Caso a embarcação seja afretada em moldes comercialmente similares aos de um arrendamento, com transferência de gerenciamento e controle, o afretador é um bareboat-charterer (afretador a casco-nu) (SARACENI, 2006).

Em relação às modalidades de contratação, incluindo as definições internacionais e as constantes na legislação brasileira, o afretamento pode ser classificado como afretamento por viagem (Voyage Charter - VCP); afretamento por tempo ou por período (Time Charter - TCP) e afretamento a casco nu (Bareboat Charter).

Quando o interesse do afretador é por transportar uma determinada carga de um porto a outro de seu interesse, os serviços de transporte são contratados por viagem (Voyage Charter - VCP). Nesse contrato, no qual o fretador se obriga a colocar o todo ou parte de uma embarcação com tripulação à disposição do afretador para efetuar uma ou mais viagens (Lei 9.432/97), toda a gestão náutica 
(gestão dos aspectos técnicos do navio) e a gestão comercial (gestão dos aspectos comerciais e de programação do navio) são do dono do navio (SARACENI, 2006).

No entanto, quando o afretador tem interesse em ter o navio sob sua gestão comercial e o contrata para carregar várias cargas durante um determinado período, tem-se o afretamento por tempo ou por período (Time Charter - TCP). Nessa modalidade, o afretador recebe a embarcação armada e tripulada para operá-la. Porém, toda a programação e as questões comerciais do navio são de responsabilidade do afretador. Ou seja, a gestão náutica é do navio, mas a gestão comercial passa a ser do afretador. A duração de um time charter depende de diversos fatores, tais como o período pelo qual o navio será necessário ao afretador; a condição do navio na entrega ao afretador e a condição estimada para o final do período (afretar um navio novo por dez anos é, em teoria, bem mais seguro do que fazê-lo com um navio de quinze anos de idade, tendo em vista que um navio de 20 anos já se encontra comercialmente no fim de sua vida útil); a legislação aplicável no país do afretador; etc. (SARACENI, 2006).

No afretamento por período, além do aluguel do navio, cabe ao afretador pagar pelos custos referentes à gestão comercial do navio, tais como combustível (bunker), custos portuários, praticagem, aluguel de lancha (exceto se o aluguel ocorrer por interesse do fretador), taxas de farol, rebocadores, taxas consulares (exceto se referentes à tripulação ou ao país da bandeira do navio), custos de canais e agenciamento do navio, entre outros custos determinados nos formulários-padrão de time charter party (SARACENI, 2006).

A modalidade em que a gestão comercial e a gestão náutica são transferidas para o afretador no momento de sua contratação é o afretamento a casco nu (Bareboat Charter). Assim, o afretador tem a posse, o uso, o gerenciamento e o controle da embarcação por um período predeterminado, incluindo o direito de designar o comandante e a tripulação, apesar de ser mantida a propriedade real e registrada do navio em nome do armador original. O navio é afretado só com sua estrutura mecânica e afretador é o responsável por tripular e comandar o navio. Neste caso, o afretador passa a figurar como armador disponente (disponent owner) da embarcação e, assim, esse navio provavelmente será afretado por tempo ou por viagem por um outro afretador, tendo como armador (dono, owner) do navio o disponente owner (SARACENI, 2006). 
No transporte marítimo, o papel do broker é o de conciliar os interesses de ambas as partes, negociando os termos e condições do contrato a ser firmado entre as partes. É o intermediário entre fretadores que procuram cargas para seus navios e afretadores que possuem cargas a movimentar, sendo remunerado através de comissão paga pelo fretador sobre os montantes recebidos no contrato (frete e sobre-estadia, aluguel etc.). O broker não é parte contratual do afretamento, apesar de ter seu nome e sua comissão citados em alguns formulários de contrato de afretamento. (SARACENI, 2006).

O aluguel do navio (hire) é pago antecipadamente em periodicidade mensal ou quinzenal e, geralmente, em dólares americanos. O aluguel somente é suspenso em casos previstos no contrato que impeçam o navio de atender às necessidades do afretador. Nesses casos, o navio estará em condição off-hire (SARACENI, 2006).

No universo do transporte marítimo, os contratos são formulários padrão elaborados por grandes empresas da categoria daquele navio. No caso dos navios petroleiros, há o Shelltime (para contratos TCP) e o Shellvoy (para contratos VCP), por exemplo. As cláusulas podem ser alteradas, mas, no formulário padrão, devem-se riscar as condições negociadas para serem excluídas e introduzir o novo texto, sendo proibido simplesmente suprimir o texto. Normalmente, essas alterações são apresentadas em cláusulas adicionais (Rider Clauses) que podem ser do afretador e do fretador (SALGUES, 2002).

\section{3. \\ Estratégia de compras no transporte marítimo}

Dagic et al. (2015), apresentam uma extensa metodologia de otimização do período de afretamento de navios e barcaças do tipo jack-up para as atividades de operação e manutenção (O\&M) dos parques eólicos offshore, visando redução dos custos de O\&M e máxima produção. Plataformas de jackup são unidades de auto-elevação que consistem de um casco flutuante contendo algumas pernas (normalmente de 3 a 6 pernas) e servem para dar estabilidade para operações de elevação em condições instáveis de mar e tempo. Nesse contexto, o estudo demonstra a influência da estratégia de afretamento desse tipo especial de navio nos custos totais de O\&M.

No mercado de compra e venda de navios, os investidores sempre enfrentaram difíceis tomadas de decisão da melhor época para investimento ou desinvestimento em razão da complexa e volátil natureza da indústria de 
transporte marítimo. Por essa razão, esse comportamento dinâmico e dos preços dos navios suas volatilidades vêm sendo o foco de muitos estudos empíricos na literatura de economia marítima. Alizadeh \& Nomikos (2007) propõem uma nova abordagem para decisões de quando investir e desinvestir no mercado do transporte marítimo. Os resultados do estudo demonstram que a relação entre preço e lucro no mercado de navios contém informações importantes sobre o comportamento futuro dos preços dos navios que podem ser usadas para definir quando investir nesse mercado.

Hesping \& Schiele (2015) citam que um exemplo ilustrativo do uso do modelo proposto por Kraljic (1983) é a compra de bunker para a navegação, querosene para aviação e combustível para caminhões, cujos produtos são fornecidos pelas mesmas empresas de combustíveis que competem entre si, como um mercado único. Por isso, Hesping \& Schiele (2015) entendem que deveriam ser tratados como uma categoria única de fornecedores e não como três produtos diferentes.

Não foram encontrados estudos específicos que relacionem estratégia de compras com a contratação de serviços de transporte marítimo. Assim, o presente estudo demonstra sua importância em trazer para academia um trabalho que aplica conhecimentos da literatura na prestação de serviços de transporte marítimo, uma área de prestação de serviços logísticos ainda pouco estudada pela academia. 


\section{Estudo de caso}

O estudo de caso apresentado neste capítulo foi realizado na empresa $X Y Z$, uma companhia verticalizada de petróleo que atua como uma empresa integrada de energia nos seguintes setores: exploração e produção, refino, comercialização, transporte, petroquímica, distribuição de derivados, gás natural, energia elétrica, gás-química e biocombustíveis.

Primeiro é apresentado o perfil da empresa e de suas atividades envolvendo o transporte marítimo. Em seguida, expõe-se a metodologia usada para conduzir o estudo de caso e, finalizando o capítulo, são demonstradas as análises pertinentes ao estudo, considerando todas as fases abordadas por Kraljic (1983).

\section{1. \\ O Transporte Marítimo na Empresa XYZ}

Considerando seu perfil, a empresa $X Y Z$ necessita realizar inúmeras variações de operações logísticas multimodais para movimentação de seus produtos, sendo seu principal e central modal, o transporte marítimo.

Tendo em vista que a maior parte de sua produção de petróleo está em campos marítimos e, em face do privilegiado extenso litoral brasileiro, as operações logísticas para transporte de petróleo e derivados em grande quantidade são, na maioria das vezes, realizadas via cabotagem e viagens de longo curso, para assim ser viável e rentável entregar seus produtos aos clientes no Brasil e em várias outras regiões do mundo.

O alívio das plataformas, operação de transferência de petróleo da plataforma produtora/ armazenadora para um navio petroleiro, é um dos processos de transferência de produtos mais importantes da cadeia de suprimentos da empresa XYZ. O custo da falta do navio aliviador é exorbitante, pois, se o petróleo armazenado não é transferido, a produção de petróleo terá que ser interrompida (top de plataforma). Além do prejuízo causado pelo tempo que a plataforma fica sem produzir petróleo, o custo para retomada de produção de uma plataforma de petróleo é elevadíssimo. Dessa forma, pode-se apresentar 
qualitativamente a relevância que o transporte marítimo tem dentro da companhia.

Por não se tratar de atividade-fim da empresa $X Y Z$, mas em face do impacto relevante que as operações marítimas têm na movimentação de seus produtos, a empresa definiu sua estratégia de terceirização da seguinte forma resumida:

- Afretamento de navios por tempo (Time Charter Party - TCP);

- Contratação de navios por viagem (Voyage Charter Party - VCP).

Com base em estudos de previsão de demanda, a empresa define um percentual estratégico para os afretamentos por tempo, onde o custo da contratação é consideravelmente mais baixo. A outra parte das operações é feita utilizando a contratação por viagem, onde os preços dos fretes são mais elevados e sofrem uma variação grande em função da disponibilidade dos navios no mercado (lei da oferta e da procura). No entanto, tal tipo de afretamento faz-se necessário, pois sempre haverá uma diferença entre a demanda realizada e a prevista. Busca-se, assim, um número menor de operações realizadas via contratos por viagem (VCP), ao mesmo tempo em que se busca o maior número de operações sob contratos por tempo (TCP). Dessa forma, evita-se ao máximo a ociosidade destes navios, já que os navios são remunerados pelo tempo que estão contratados, independente de estarem operando ou não.

O afretamento de navios na logística de uma empresa de petróleo verticalizada como a do presente estudo, que atua desde a exploração de petróleo até a venda de seus derivados, nitidamente se diferencia de outras compras da empresa, tendo em vista ser uma compra intimamente ligada à atividade-fim. Além disso, o ganho financeiro de uma boa contratação, considerando-se os elevados valores movimentados nessas compras (na ordem de bilhões de dólares ao ano), pode ser bastante significativo para o resultado da diretoria e, por conseguinte, da própria empresa.

As contratações destinadas aos alívios de plataforma, ao abastecimento das distribuidoras de combustível e ao suprimento interno da companhia $X Y Z$, isto é, relativas às operações geridas pela logística de produtos da empresa XYZ, são afretadas na modalidade TCP em cerca de $80 \%$ dos casos (considerando subsidiária e outros). A contratação em TCP tem um horizonte de longo prazo na qual o poder de barganha do mercado e a força do comprador 
variam ao longo do ano. Assim, as contratações podem ser feitas mediante dias de negociação quanto às condições do serviço a ser prestado pelo fretador.

A outra parte da contratação de navios é feita em VCP e tem características de mercado bem diferentes da contratação em TCP, pois é um processo em que a agilidade do fechamento do negócio é o ponto crítico do processo de contratação. Nessa contratação, o valor do frete oscila muito e pode apresentar diferenças significativas de uma semana para outra em função das condições de mercado. O mercado tem uma força grande frente ao poder de negociação do afretador, pois a contratação visa o transporte específico de uma carga numa data próxima à busca pelo navio no mercado e, assim, não há margem suficiente de tempo para aguardar um período mais favorável. Portanto, o poder de barganha dos armadores se torna preponderante e a estratégia de compras restrita ao atendimento das exigências do mercado naquele momento.

Ademais, os contratos entre a empresa e sua a subsidiária integral tem características muito diferentes do que os contratos do navio em TCP de um armador externo. É uma relação dentro do mesmo grupo empresarial em que as condições contratuais são extensivamente negociadas para que ambos, fretador e afretador, obtenham ganhos que contribuam tanto para as empresas individualmente quanto para o grupo como um todo.

Dessa forma, tais contratos serão estudados e analisados dentro do portfolio de Kraljic (1983), utilizando-se pesos para mensurar a importância de cada categoria nos eixos da matriz.

\section{2.}

\section{Metodologia de condução do estudo de caso}

O presente item demonstra a metodologia usada no estudo de caso para avaliar a importância estratégica do afretamento de navios da logística do abastecimento da empresa XYZ.

O trabalho, como será exposto adiante, utilizou-se de entrevistas com funcionários da área de afretamento e de programação de navios da empresa XYZ para estabelecer o posicionamento dos contratos de afretamento na matriz de Kraljic. Como no modelo proposto por Kraljic (1983) não é descrito qual deve ser o método de atribuição de pesos para os eixos, para cada eixo (complexidade do mercado e importância das compras) foi proposta uma 
classificação que possibilite posicionar aquele agrupamento de contratos em um dos quadrantes da matriz.

As etapas do estudo seguem o diagrama de passos da Figura 12:
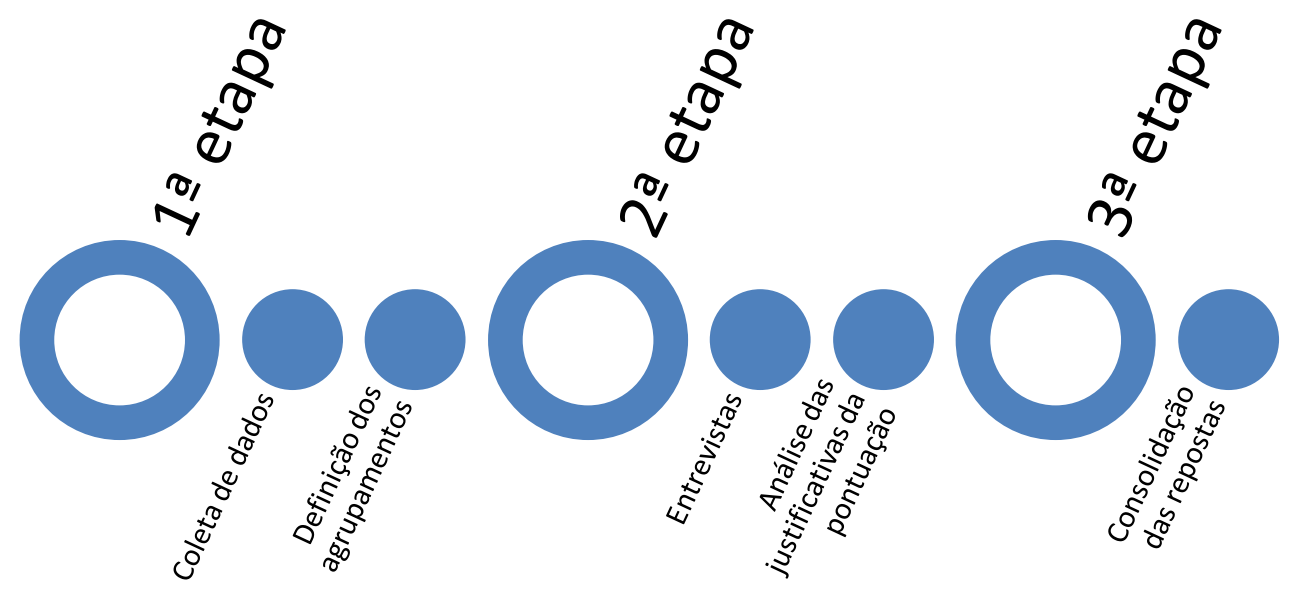

Figura 12 Diagrama de passos do estudo de caso

Fonte: Autora

\section{1a etapa: Coleta de dados e definição de agrupamentos}

Para obtenção dos dados a serem usados no presente estudo, foi solicitada à gerência de afretamento de navios da logística da empresa XYZ uma listagem com os contratos em afretamento por TCP (incluindo os contratos com a subsidiária) e VCP. Após o levantamento dos navios contratados no período da coleta ( $1^{\circ}$ semestre de 2015), definiu-se amostra, composta por 160 contratos em TCP, a ser estudada e também qual tipo de classificação seria usado.

Então, foi feita a classificação dos itens para aplicação do método de Kraljic (1983). Foram criados assim os agrupamentos por contratação, armadores e classes.

\section{$\underline{2^{\mathrm{a}}}$ etapa: Entrevistas e análise das justificativas da pontuação}

Após a coleta e agrupamento dos dados, foram realizadas entrevistas com três funcionários da gerência de afretamento e dois da gerência de programação de petróleo e derivados, dentre eles, analistas de comercialização e logística, 
engenheiros de produção e técnicos de suprimento. As entrevistas foram feitas com funcionários com média de 10 anos de trabalho na empresa, na área de logística. A alta complexidade do assunto exige uma equipe especializada com experiência para desenvolver suas atividades de forma segura e rentável, o que faz com que os profissionais se mantenham por longos anos dentro de uma mesma função.

\section{$\underline{3^{\text {a }} \text { etapa: Consolidação de respostas }}$}

As entrevistas foram realizadas baseadas numa proposta de classificação dos contratos inicialmente apresentada pela autora, para que a sugestão da aplicação do estudo de caso fosse bem compreendida por todos os funcionários entrevistados. Durante as entrevistas, os funcionários apresentaram suas interpretações e sugeriram novos agrupamentos e classificações a serem estudados e consolidados pela autora.

$\mathrm{Na}$ etapa final de consolidação das respostas, os entendimentos da autora e dos funcionários das gerências entrevistadas foram descritos e expostos na matriz de Kraljic e resultaram na versão final apresentada no estudo.

\section{3. Resultados}

Atualmente, o afretamento de navios da empresa $X Y Z$ não tem qualquer tipo de classificação de estratégia proposta pela literatura para a contratação da prestação de serviços de transporte marítimo. O estudo apresenta uma proposta inicial de classificação dos itens e posicionamento destes na matriz de Kraljic (1983) para que novas estratégias de compras possam ser estabelecidas baseadas na literatura especializada do assunto.

\subsection{1. \\ Critérios para definição dos agrupamentos}

Primeiramente, dividiu-se a frota contratada em dois grupos por tipo de contratação: VCP e TCP. Os navios contratados em VCP, cuja duração de tempo gira em torno de dias e a gestão da navegação fica inteiramente sob responsabilidade do armador, foram considerados como parte de um grupo único, pois a variação de navios contratados no horizonte de apenas um mês 
tende a ser muito dinâmica. Os navios, individualmente, têm pouca representatividade contratual, já que o retrato e o valor da listagem de hoje pode ser extremamente diferente dos da semana que vem. Isso acontece, tendo em vista que o preço do frete de navios (VCP) pode oscilar consideravelmente ao longo de um mês, pois a lei de oferta e procura num mercado de contratos de tão curto prazo faz com que os preços sejam muito diferentes em função da procura naquele exato momento de contratação. Dessa forma, em razão da variabilidade do mercado e da dificuldade de classificá-los quanto à complexidade do mercado e à importância da compra, os navios VCP foram considerados, no presente estudo, com um grande grupo à parte. Enquanto os navios e os valores de frete (VCP) têm uma variação grande ao longo algumas semanas na listagem dos navios VCP, a relação dos navios afretados em TCP têm apenas algumas mudanças resultantes do término de alguns contratos naquele período. Assim, os navios afretados em TCP foram subdivididos em outros grupos.

Nos contratos em TCP, verificou-se que uma grande variedade de armadores presta serviço para a empresa $X Y Z$, muitos com apenas um contrato com a empresa, mas, por outro lado, outros possuindo mais de um contrato. Os agrupamentos por armadores foram, então, considerados no estudo e foram denominados "classificação por armadores".

Em seguida, foram subclassificados os contratos em TCP em contratos com armadores com custo percentual - em relação ao total contratado em TCP maior que um por cento e menor que um por cento.

Ademais, as contratações em TCP podem ser divididas em subgrupos em função da classe dos navios, pois visivelmente as condições de mercado e de importância das compras apresentam variações entre os subgrupos sugeridos. Tal organização será, daqui em diante, denominada "classificação por classes de navios", conforme Tabela 3, Tabela 4 e Anexo I deste estudo.

\begin{tabular}{|l|l|l|}
\hline Agrupamento de classes & Descrição resumida & Classes participantes \\
\hline Navios DP & Alívio de plataformas offshore & C, F e H \\
\hline Navios VLCC & Petróleo - navegação de longo curso - importação e exportação & G e I \\
\hline Navios de cabotagem & Navios usados na costa brasileira para cabotagem de derivados & A, B, D e E \\
\hline Navios gaseiros & Gaseiros & L, M e N \\
\hline Navios de especiais & Asfalto e bunker & J e K \\
\hline
\end{tabular}

Tabela 3 Agrupamento por classes de navio

Fonte: Autora 


\begin{tabular}{|l|l|}
\hline Letras correspondentes & Classe \\
\hline Petróleo + Derivados claros e Escuros & \\
\hline A & Handysize \\
\hline B & Midrange \\
\hline C & Midrange DP \\
\hline D & Panamax \\
\hline E & Aframax \\
\hline F & Aframax DP \\
\hline G & Suezmax \\
\hline H & Suezmax DP \\
\hline I & VLCC \\
\hline Produtos Especiais (GLP, asfalto, bunker) & \\
\hline J & Asfalto \\
\hline K & Bunker \\
\hline L & GLP (pressurizado) \\
\hline M & GLP (LGC e VLGC) \\
\hline
\end{tabular}

\section{Tabela 4 Classe do navio e letra correspondente}

Fonte: Autora

Em resumo, os navios foram agrupados de duas formas, representados pela Figura 13 e pela Figura 14:

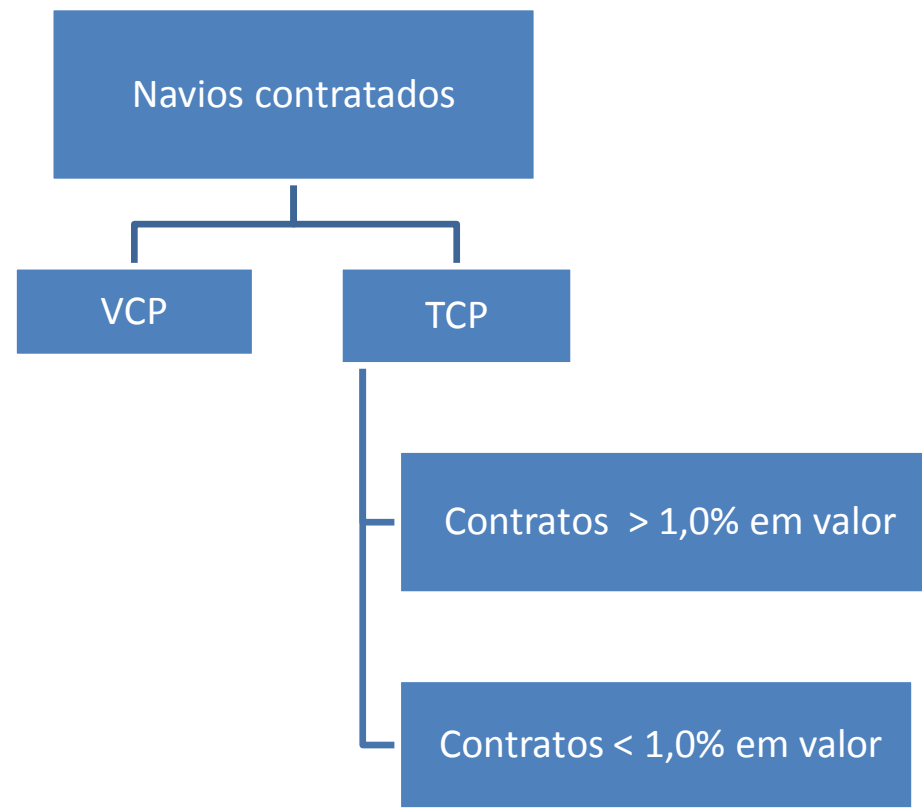

Figura 13 Agrupamento por tipo de contratação e por armador 


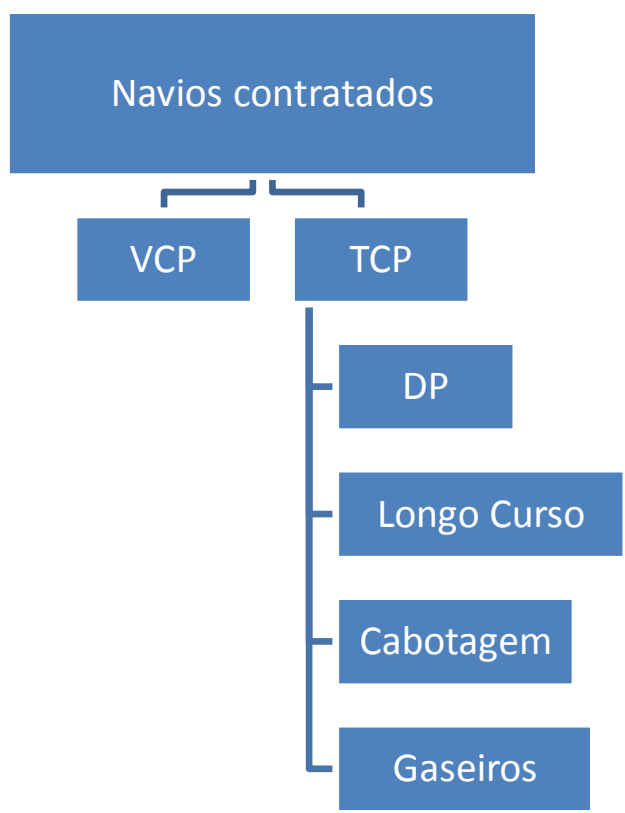

Figura 14 Agrupamento por tipo de contratação e por classe

Fonte: Autora

\subsection{2.}

\section{Análise dos eixos}

Para avaliação do eixo de complexidade do fornecedor, e para guiar a avaliação dos funcionários entrevistados, foram apresentadas as seguintes perguntas ao lado da matriz originalmente proposta pela autora:

"Há uma baixa oferta do serviço no mercado brasileiro? Há poucos navios dessa classe/agrupamento disponíveis para o mercado brasileiro, considerado marginal, pois o Brasil encontra-se fora do eixo golfo americano - Europa extremo oriente (far east)? Os navios dessa classe/agrupamento são disputados por muitas empresas afretadoras?"

Para as perguntas acima, quanto menor a oferta, maior a complexidade e a pontuação a ser atribuída.

No eixo importância das compras, os aspectos a serem analisados foram sugeridos na forma dos questionamentos que se seguem:

"Qual o custo do afretamento desse agrupamento de navios? Os valores envolvidos são elevados, considerando o faturamento da diretoria? A falta da prestação do serviço contratado no afretamento de navios tem impacto relevante no faturamento e na operacionabilidade da empresa XYZ?" 
No caso das perguntas referentes à importância das compras, quanto maiores os custos, maior a importância e o peso para aquele agrupamento.

Para propor pesos para os agrupamentos em cada um dos eixos da matriz foi sugerida a classificação alta ou baixa para cada uma dos eixos, conforme Figura 15 abaixo:

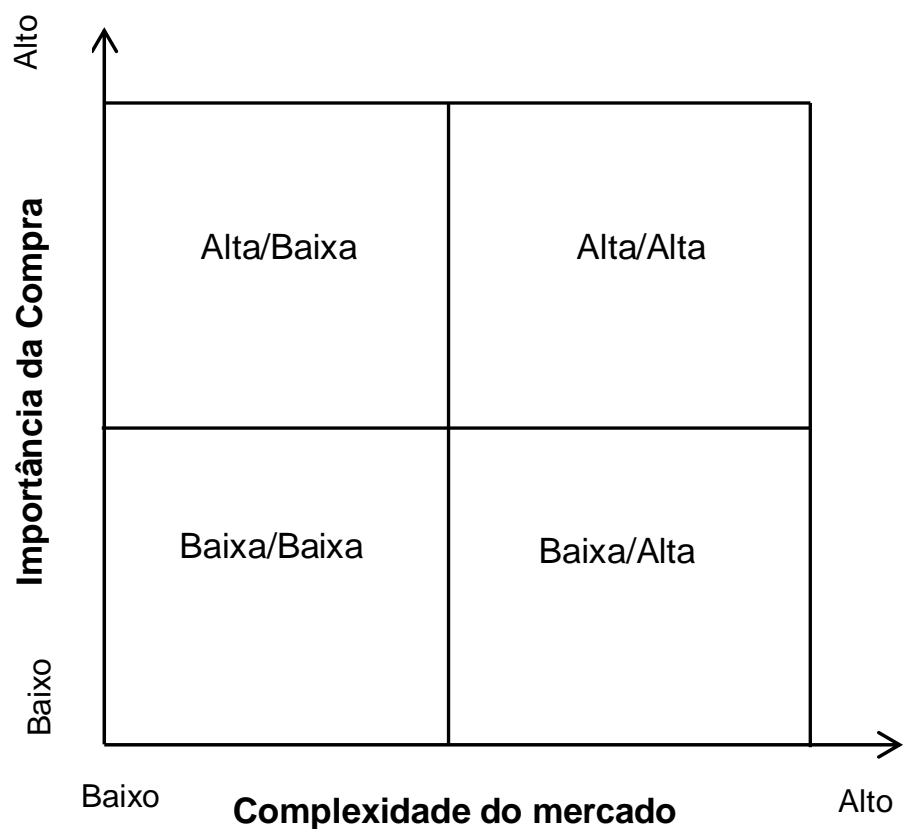

Figura 15 Posicionamento na matriz segundo proposta de classificação dos eixos

\subsection{3.}

\section{O posicionamento na Matriz de Kraljic}

Os navios contratados em TCP foram agrupados por armadores e ordenados de forma decrescente pelo percentual de valor contratado, conforme Apêndice I do presente estudo. Os armadores cujos valores de contratação são inferiores a $1,0 \%$ foram considerados como um grupo único e os principais armadores dos contratos em TCP foram identificados, conforme demonstrado na Figura 16. 


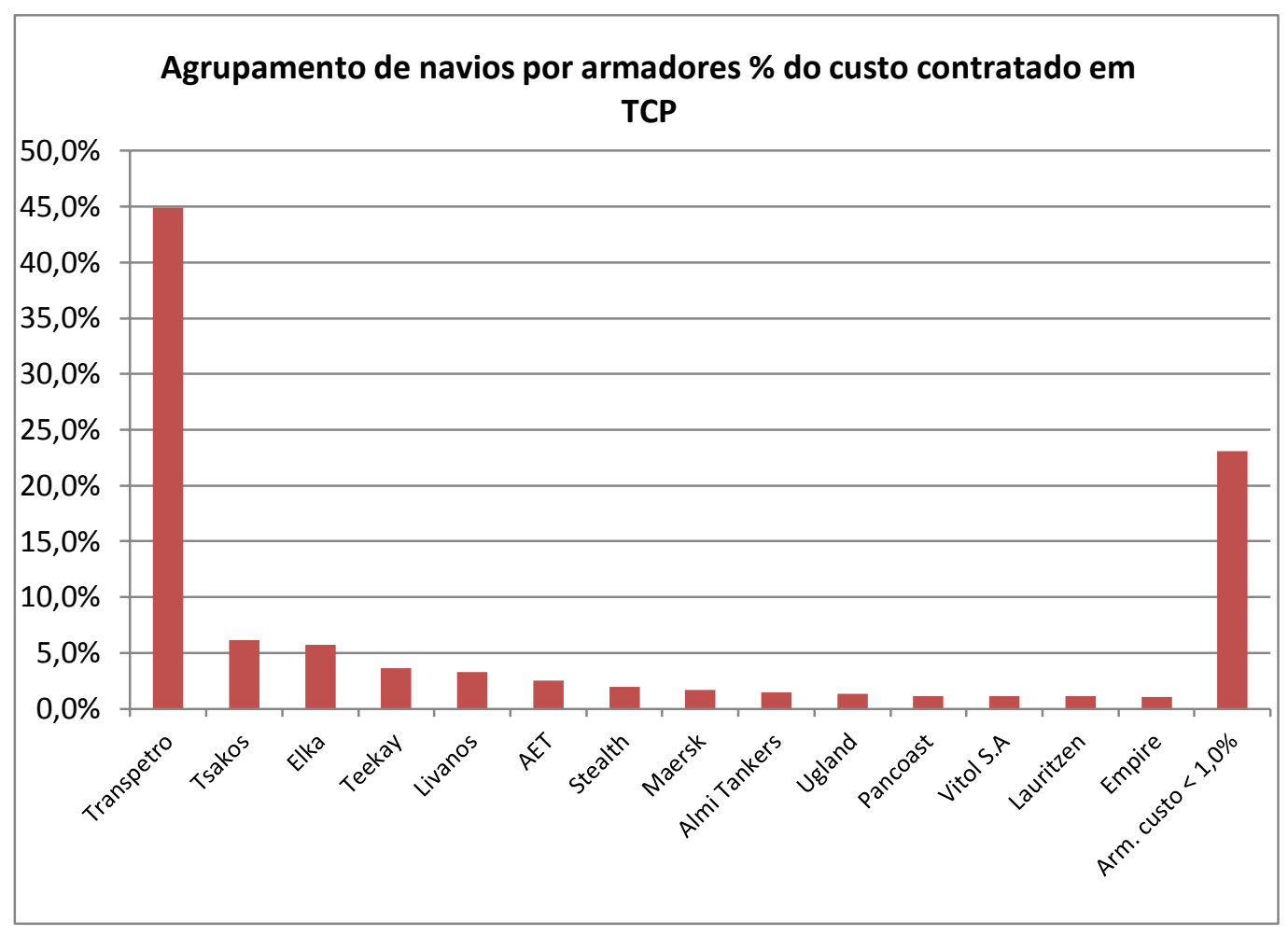

Figura 16 Gráfico com principais armadores dos contratos em TCP

Assim, cada grupo de armadores foi identificado para ser analisado em função das classes dos navios contratados. Para facilitar a classificação, primeiramente os navios foram subclassificados como navios DP e navios convencionais (aqueles que não possuem equipamento de posicionamento dinâmico):

- Transpetro - 44,9\% do custo total contratado em TCP (18 navios DP e 35 convencionais);

- Tsakos $-6,1 \%$ do custo (2 navios DP e 7 convencionais);

- Elka - 5,7\% do custo (2 navios DP e 7 convencionais);

- Teekay - 3,6\% do custo (2 navios DP e 2 convencionais);

- Livanos $-3,3 \%$ do custo (7 navios convencionais);

- AET - 2,5\% do custo (2 navios DP);

- Stealth $-1,9 \%$ do custo (6 navios convencionais);

- Maersk - 1,6\% do custo (3 navios convencionais);

- Almi Tankers $-1,4 \%$ do custo (3 navios convencionais);

- Ugland $-1,4 \%$ do custo (1 navio DP);

- Pancoast $-1,1 \%$ do custo (3 navios);

- Vitol $-1,1 \%$ do custo (6 navios convencionais); 
- Lauritzen - 1,1\%do custo total (1 navio DP);

- Empire - 1,0\% do custo total (3 navios convencionais);

- $\Sigma$ armadores com custos individuais $<1,0$ do custo $-23,0 \%$ do custo (53 navios convencionais)

Os navios em VCP, conforme explicado no item 4.3.1, foram considerados como um grupo único.

Propôs-se, então, o seguinte posicionamento dos contratos na matriz de Kraljic (Figura 17), cuja tabela encontra-se no Apêndice II, e cuja validação foi feita pelos mesmos especialistas das áreas de afretamento de navios e programação de petróleo e derivados mencionados no item 4.2: 


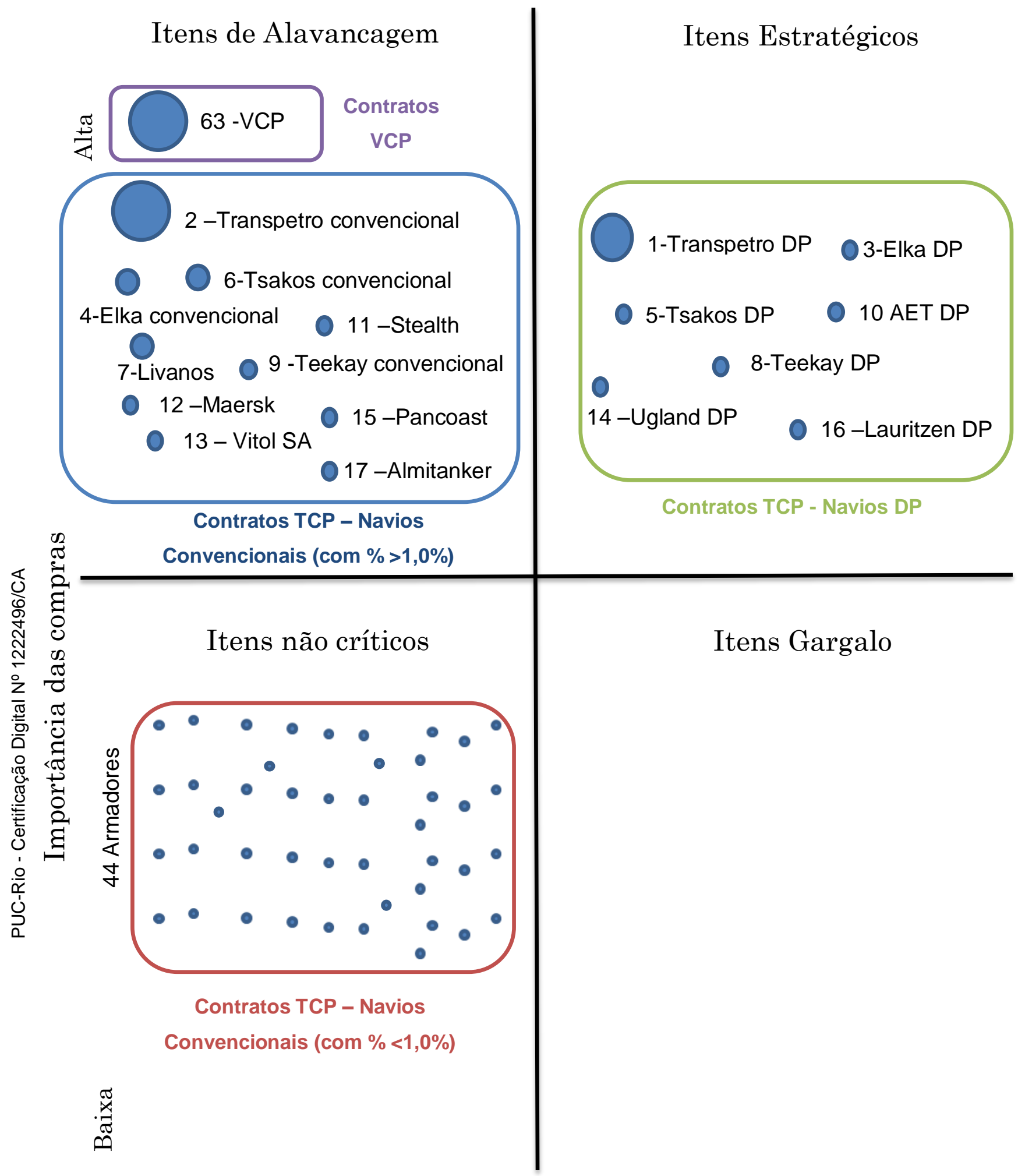

Baixa

Complexidade do Mercado

Alta

Figura 17 Posicionamento dos contratos na Matriz de Kraljic 
Para posicionar os armadores nos quadrantes acima propostos na Matriz de Kraljic, os navios foram analisados e posicionados de acordo com os seguintes aspectos:

A) Contratos TCP - Navios DP:

Complexidade do mercado: Alta

Os navios DP têm elevado custo de produção. São navios que possuem um sistema de controle diferenciado dos navios convencionais - o sistema de posicionamento dinâmico (Dynamic Position) - que mede e quantifica propriedades ambientais (vento, maré, etc.) e envia comandos para os propulsores para combater essas forças e manter a embarcação parada, ou movê-lo ao longo de uma faixa específica. Por serem navios especializados, com alta sofisticação tecnológica e demanda específica cuja substituição por outro tipo muitas vezes não é viável, pois as normas de segurança em plataformas off-shore modernas exigem que o alívio seja feito por navios DP, tais navios têm baixa disponibilidade no mercado mundial.

Importância das Compras - Alta

Em razão dos custos de construção dos navios DPs serem bem elevados, os contratos tendem a ser celebrados por períodos mais longos (pois ao contrário dos navios convencionais, não há mercado spot para navios aliviadores). Além disso, há uma importante preocupação estratégica sobre a contratação desse tipo de navio, já que o custo da falta é muito grande, pois pode ocasionar parada de produção de uma plataforma de petróleo. A parada de uma plataforma ocasiona custos na perda da produção do petróleo em si (durante o tempo da parada), além de acarretar uma nova partida de produção, cujos custos e complexidade podem ser ainda mais elevados.

B) Contratos TCP - Navios convencionais (com \% >1,0\%)

Complexidade do mercado - Baixa

No caso dos navios convencionais, ao contrário dos navios DP, o mercado substituidor tem múltiplos fornecedores e com suprimento abundante, ou seja, a empresa $X Y Z$ tem baixa vulnerabilidade frente ao mercado fornecedor. $O$ mercado é amplo e com alta competitividade. 
B1) Itens com percentual de compras $>1,0 \%$ do total

Importância das Compras - alta

Os contratos com navios convencionais cujo percentual de aluguel do armador seja maior que 1,0\% foram considerados como contratos com alta importância das compras, em razão do seu impacto nos lucros, considerando que cada armador possui uma parcela significativa dos contratos.

B2) Itens com percentual de compras $<1,0 \%$ do total

Importância das Compras - baixa

Nesse caso, os armadores possuem contratos cuja soma representa um valor baixo comparado ao valor total.

C) Contratos VCP

Complexidade do Mercado - baixa

Geralmente são navios de claros ou escuros contratados no mercado de navios convencionais para cumprirem um determinado transporte de uma carga de importação ou exportação. O mercado substituidor tem múltiplos fornecedores e com suprimento abundante, ou seja, a empresa XYZ tem baixa vulnerabilidade frente ao mercado fornecedor. O mercado é amplo e com alta competitividade.

Importância das compras - alta

Em razão do número grande de contratos num determinado período, tendo em vista que cada contrato representa somente uma única viagem, o grupo de contratos em VCP foi considerado como de alta importância das compras.

\section{4.}

\section{Análise dos resultados}

Atualmente para a empresa $X Y Z$ os processos que envolvem 0 afretamento de navios seguem apenas os critérios de isonomia, transparência e economicidade da contratação, não existindo na prática, ainda, aplicação de conhecimentos da literatura de gestão de contratos para essa área da empresa.

Analisando os contratos posicionados nos quadrantes da matriz de Kraljic (1983), o presente trabalho propõe a abordagem em quatro fases de Kraljic (1983) para a empresa XYZ definir suas estratégias visando minimizar vulnerabilidades de suprimento e aproveitar ao máximo seu potencial de 
compras: classificação dos requisitos de contratação, análise de mercado, posicionamento estratégico e planos de ação.

\subsection{1.}

\section{Fase 1 - Classificação dos requisitos da contratação}

Cada uma das quatro categorias (itens estratégicos, itens gargalo, itens de alavancagem e itens não críticos) requer uma abordagem de contratação distinta, cuja complexidade é proporcional a implicações estratégicas (Kraljic, 1983).

Após o posicionamento dos contratos na matriz importância das compras versus complexidade do mercado, cada categoria encontrada para o grupo estudado teve uma análise dos possíveis requisitos para a sua contratação.

- Itens estratégicos (Navios em TCP - navios DP)

Para esses itens de contratação, a empresa $X Y Z$ deverá ter como principais tarefas: previsão de demanda precisa, pesquisa de mercado detalhada, contratações de longo prazo, análises de risco e planos de contingência. Para isso, precisará de dados de mercado altamente detalhados, de curvas de tendência de demanda e suprimento, curvas de custo dos armadores e boa inteligência competitiva. Tais contratações, por se tratarem de decisões estratégicas, deverão ser tomadas em alto nível corporativo (ex. alta diretoria).

- Itens de Alavancagem - (navios em TCP, convencionais, com \% $>1,0 \%$; e navios em VCP).

Nesse grupo, onde a complexidade do mercado não é considerada alta, deve se explorar todo o poder de compra da empresa, selecionando-se os armadores com quem se celebrarão contratos, estabelecendo-se estratégias de negociação de preço alvo; e fazendo-se um mix de contratos TCP (contratos por tempo) e VCP (contratos por viagem). As informações requeridas para executar as tarefas mencionadas neste parágrafo são bons dados de mercado, planejamento de curto-médio prazo, dados precisos dos armadores e alguma previsão de preços. Tais decisões deverão estar em níveis de alto escalão da empresa (ex. gerentes executivos). 
- Itens não críticos (navios em TCP - Convencionais - com \% $>1,0 \%)$

As contratações desse grupo deverão buscar uma padronização de seus navios contratados, usando análises de mercado simples e modelos de otimização de inventário nas suas contratações. Por serem itens não críticos, uma boa visão do mercado, com curta previsão de demanda deverão ser suficientes para executar as tarefas propostas. Decisões, nesse grupo, podem ser tomadas no mais baixo nível de decisão existente na empresa (ex. gerentes abaixo das gerências executivas).

\subsection{2.}

\section{Fase 2 - Análise de mercado}

Em seguida, a companhia deve analisar o poder de barganha de seus fornecedores frente à sua própria força como cliente. Assim, para cada quadrante foram analisados os principais aspectos considerados para classificação do eixo complexidade do mercado, os quais são a disponibilidade dos navios para o mercado brasileiro e os potenciais custos no evento de não entrega do navio.

- Itens estratégicos (Navios em TCP - navios DP)

Para os navios DP, os custos de não ter o navio ou de ter um com qualidade inadequada têm um altíssimo impacto nos custos logísticos do alívio de plataformas de petróleo. Assim, uma mudança frequente nos fornecedores (armadores) deste tipo de navio pode acarretar em riscos potenciais na qualidade do serviço prestado, o que ocasionará aumento de tais custos logísticos. Por isso, contratos de longo prazo com empresas renomadas no mercado são recomendados para contratos estratégicos. Além disso, é interessante para ambas as partes contratos de longuíssimo prazo ( $>20$ anos) com o objetivo de custear o alto valor de construção de navios DP. Quanto à disponibilidade dos navios DP para o mercado brasileiro, considerado marginal ao mercado principal predominante no eixo Europa - Norte da África - Golfo Arábico, não se observa criticidade pois, por serem realizados contratos de longo prazo, o local onde se encontra o navio no momento da negociação não interferirá nos preços do aluguel diário dos navios. 
- Itens de Alavancagem - (navios em TCP, convencionais, com \% $>1,0 \%$; e navios em VCP).

Para esse quadrante, o custo da falta pode ser considerado alto em razão do grande volume de contratos desses dois grupos. Para os navios em VCP, a disponibilidade do navio é mais crítica do que para os navios em TCP, pois como será feita uma única viagem, o frete a ser pago pela empresa $X Y Z$ será maior que por empresas posicionadas no eixo principal do mercado de commodites de petróleo e derivados. Porém, por se tratar de um serviço de transporte mundial, somente o aumento do preço do frete será impactado, não havendo outras restrições na prestação do serviço de transporte marítimo para empresas posicionadas em mercados atualmente ainda considerados marginais.

- Itens não críticos (navios em TCP - Convencionais - com \% $>1,0 \%)$

Para esses contratos, a criticidade do mercado é relativamente baixa frente aos outros grupos. Por se tratarem de armadores com baixo volume de contratação com a empresa $X Y Z$, o impacto da falta da prestação desse serviço é baixo comparado com armadores com maiores valores em contrato com a empresa.

\subsection{3.}

\section{Fase 3 - Posicionamento estratégico}

Nessa fase, a companhia deve posicionar os contratos identificados na matriz da fase 1 como "itens estratégicos" na matriz de portfólio de compras, conforme Figura 17(KRALJIC, 1983). No presente estudo, tais contratos identificados como estratégicos foram os navios DP contratados em TCP, destacados abaixo na Figura 18. 


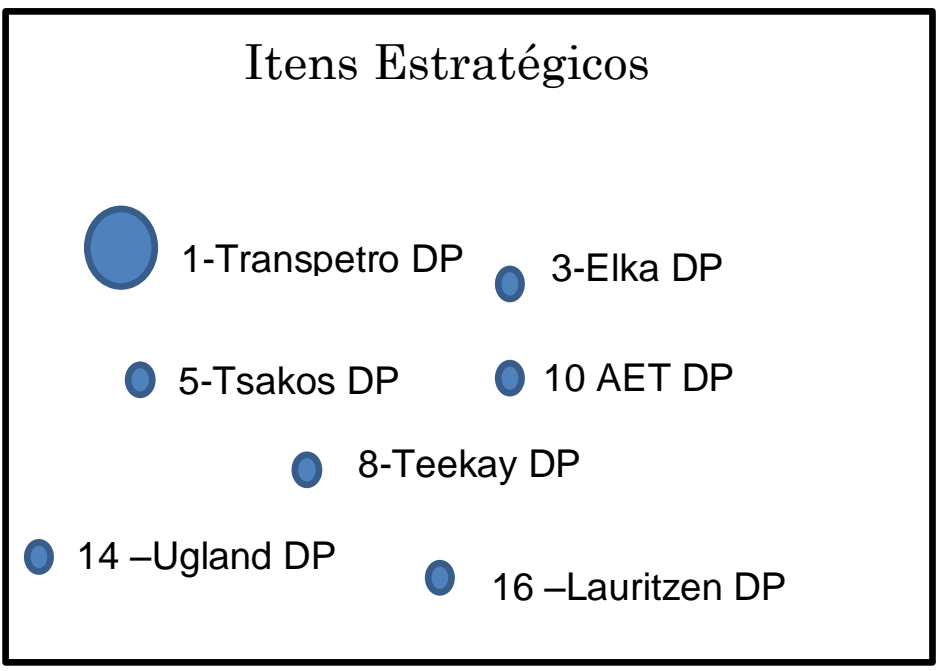

Figura 18 Itens posicionados como estratégicos na Matriz de Kraljic (1983)

Dessa forma, os contratos acima foram classificados na matriz de portfolio de compra:

- Diversificada: Elka DP, Tsakos DP, Teekay DP, AET DP, Ugland DP e Lauritzen DP

Nesses itens, onde o papel da companhia no mercado de suprimento é secundário e o papel dos fornecedores é mais forte, a empresa deve procurar por múltiplos fornecedores. A empresa pode aumentar seus gastos em pesquisa de marketing ou relacionamento com clientes, ou mesmo investir em pesquisa e desenvolvimento em conjunto com os fornecedores. Em suma, a companhia precisa ter opções de suprimento do serviço com vários fornecedores ou até mesmo tipos diferenciados de serviço. Nesse caso, onde a companhia barganha do lado mais fraco, a empresa deve oferecer, por exemplo, obrigações em contratos de logo prazo ou preços mais altos, visando não colocar em risco o suprimento considerado estratégico para a companhia (KRALJIC, 1983).

- Agressiva (explorar): Transpetro DP

No contrato com a sua subsidiária, a empresa $X Y Z$ tem um papel dominante. A força do fornecedor é mais baixa em comparação aos contratos com armadores externos, assim, o risco de desabastecimento também será mais baixo, o que possibilita que a empresa possa pressionar sua subsidiária a conseguir preços mais favoráveis. 


\subsection{4.}

\section{Fase 4 - Planos de ação}

Em curto prazo, para contratos nos quais o posicionamento estratégico indicado é a diversificação, como no caso dos contratos mencionados no item 4.4.3, a companhia deve consolidar sua posição no suprimento aceitando preços mais elevados, e cobrindo todo o volume de serviço requerido com contratos firmes e preferencialmente de longo prazo. No entanto, para reduzir o risco de dependência de longo prazo, a empresa deve também procurar por fornecedores alternativos e até mesmo considerar uma integração entre fornecedor e empresa que possibilite a construção de navios dentro da própria companhia.

Nessa fase, então, a companhia deve explorar uma gama de cenários de suprimento em que possam ser vistas as opções para um suprimento de longo prazo seguro e também que possam ser exploradas oportunidades de contratos de prazos menos longos, claramente definindo riscos, custos e implicações estratégicas. Além disso, tais cenários devem possibilitar que a companhia desenvolva uma opção de preferência com objetivos, passos, responsabilidades e medidas de contingência demonstrados em detalhes para aprovação da alta diretoria e posterior implantação. O produto final é um plano de ação com estratégias sistematicamente documentadas para contratos considerados estratégicos que especifica os critérios e o tempo necessários para futuras ações (KRALJIC, 1983). 


\section{5 \\ Conclusões e Recomendações}

O presente estudo teve como objetivo principal a aplicação e a avaliação do modelo de portfólio de compras de Kraljic (1983) para o afretamento de navios na área de transporte marítimo de uma empresa verticalizada de petróleo.

Deste modo, para responder esta questão, o estudo foi estruturado com dois objetivos secundários:

i. Identificar e descrever as peculiaridades do processo de afretamento de navios em uma empresa de petróleo.

ii. Analisar e propor a matriz de portfólio de Kraljic para o afretamento de navios nessa empresa, classificando os tipos de afretamento e os posicionando nos quadrantes da matriz;

O uso do modelo de Portfolio de Kraljic neste estudo se justifica, pois tratase de um modelo referencial na literatura, utilizado para elaboração de estratégias de compras de empresas e usado como base para inúmeros outros modelos de estratégia de compras.

Utilizou-se a metodologia de estudo de caso por ser considerada a mais adequada para o tipo de estudo proposto, que examina um fenômeno atual que foge do controle do pesquisador. Foram realizadas entrevistas e discussões com especialistas que trabalham na gerencia de afretamento e nas gerências de programação de petróleo e derivados da empresa avaliada.

Dentro do estudo de caso realizado, constatou-se que alguns contratos fazem parte do quadrante de alavancagem, outros do quadrante estratégico e outros dos itens não críticos da matriz de Kraljic (1983).

Quanto aos itens não críticos, os riscos de suprimentos para a empresa são menores e medidas de simplificação no processo de contratação devem ser adotados pela empresa. Analisando a gestão de contratos e os estudos de Kraljic (1983) em especial, o processo pode ser simplificado, considerando estudos de mercado mais simples que o atualmente existentes. Também deve ser simplificado o processo de aprovação de cada contrato, diferenciando-os dos contratos considerados como estratégicos ou de alavancagem. Porém, para esse grupo, o processo de afretamento no mercado dentro da empresa já se 
encontra adequado aos preceitos da academia, pois são lançados processos de concorrência padronizados, com contratos rígidos e preços negociados com todos os concorrentes.

Para os itens que se enquadram como de alavancagem, os riscos de suprimento já são um pouco maiores e é necessário um cuidado maior quanto ao processo de aprovação do afretamento de cada navio, recomendando-se manter em alçada executiva da corporação. Os contratos podem continuar sendo um mix de contratos por tempo e por viagem, o que traz flexibilidade na contratação em função de mudanças na demanda da empresa ou mesmo das tarifas do mercado. O processo de contratação no mercado precisaria ser mais individualizado, visando um aproveitamento maior quanto à barganha de preços e condições.

Por outro lado, os itens posicionados como estratégicos necessitam de grande segurança quanto ao serviço prestado pelos navios contratados, o que demanda contratos de longo prazo. Atualmente, a empresa já possui navios em contrato que foram construídos pelos fornecedores para o atendimento do alívio de plataformas de produção de petróleo da empresa XYZ. Tais parcerias devem ser estimuladas, pois trazem benefícios quanto o suprimento da empresa XYX assim como garantia de retorno financeiro para o fornecedor, considerando em especial o alto custo de construção desse tipo de navios (DP). Nessa linha, a empresa $X Y Z$ afreta navios de sua subsidiária integral, o que corrobora 0 entendimento da literatura sobre o assunto. Para tais navios, o processo de contratação deve ser único e extremamente cuidadoso, preferencialmente iniciando-se com antecedência superior aos contratos dos dois outros quadrantes onde foram posicionados os contratos da empresa $X Y Z$.

Atualmente, o processo de aprovação do afretamento dentro da diretoria de abastecimento da empresa XYZ é único, diferenciando apenas a alçada da aprovação da contratação, que depende exclusivamente do valor de cada contrato em si. Para todo afretamento dentro da diretoria, há um estudo amplo de previsão de mercado e demanda, assim como também o processo de contratação de cada navio no mercado é único, visando somente os requisitos de transparência, isonomia e menor custo. No entanto, o estudo de caso presente pretende trazer à luz do conhecimento da empresa o que a literatura traz sobre gestão de compras e aplicar no afretamento de navios o que for adequado e possível para a companhia. 
Embora tenha sido aplicado em apenas uma empresa pertencente ao segmento de petróleo, devido ao porte da empresa e seu domínio do mercado nacional, o estudo de caso claramente mostra sua importância, pois se trata de um trabalho pioneiro que aborda a contratação de serviços de transporte marítimo com modelos de gestão de compras da literatura.

\section{1 . Recomendações para Estudos Futuros}

Neste estudo, observou-se que as empresas vêm apresentando uma evolução ao longo dos anos no processo de compras. No entanto, o estudo de caso teve como foco apenas uma empresa pertencente à indústria de petróleo brasileira, com o objetivo de trazer um primeiro entendimento da aplicação dos conceitos de gestão de compras para os processos de afretamento de navios. Assim, recomenda-se que estudos futuros sejam aplicados na gestão de compras do afretamento a outros setores da economia uma vez que a proposta é pioneira, pois não foram encontrados estudos relacionando os temas.

Outra recomendação para estudos futuros consiste em um maior detalhamento da aplicação de Kraljic, tais como desenvolver um modelo em mais de duas dimensões onde possam ser incluídos aspectos relevantes das transações comerciais atuais, como o conceito de vantagem competitiva e sustentável nos relacionamentos entre as empresas (PAGELLI \& WU, 2009). 


\section{Referências bibliográficas}

ALIZADEH, A.; HUANG, C.; DELLEN, S. A regime switching approach for hedging tanker shipping freight rates. Energy Economics. 49, p.44-59, 2015

ALIZADEH, A \& NOMIKOS, N. Investiment timing and trading strategies in the sale and purchase market for ships. Transportation Research Part B, 41, p. 126-143, 2007.

ARYA, A., FELLINGHAM, J. \& MITTENDORF, B. Make-or-buy in the presence of uncertainty and private information. Journal of Accounting Education, ed.23, p.189-203, 2005.

ASHENBAUM, B. Designing the supply chain for production and aftermarket needs. CAPS Research Critical Issue Reports, 2006.

BALLOU, R.H. Gerenciamento da Cadeia de Suprimentos Planejamento, Organização e Logística Empresarial. São Paulo. Bookman, 2002.

BAILY, P.; FARMER, D.; JESSOP, D.; JONES D.; Compras: princípios e administração. São Paulo: Editora Atlas. 2000.

BENSAOU, M. Portfolios of Buyer-Supplier Relationships. Sloan Management Review, v. 40, n. 4, 35-41. 1999.

BOWERSOX, D., ClOSS, D. \& COOPER, M.; Gestão da Cadeia de Suprimentos e Logística. Rio de Janeiro: Elsevier, 2007. 
BOWERSOX D. J. \& CLOSS D. J. Logistical Management: The Integrated Supply Chain Process. New York, MacGraw-Hill Companies, Inc., 1996.

CANNON, J., DONEY, P., MULLEN, M. \& PETTERSEN, K. Building long term prientation in buyer-supplier relationships: the moderate role of culture. Journal of Operational Management, 28, 506-521, 2010.

CARR A. \& SMELTZER L. An empirically based operational definition of strategic purchasing. European Journal of Purchasing \& Supply Management, vol.3. n.4, p.199-207, 1997.

CARR A. \& SMELTZER L. An empirical study of the purchasing and supply management skills required for the new millennium. The 9th International Annual IPSERA Conference and The Third Annual North American Research Symposium on Purchasing and Supply Chain Management, University of Western Ontario, London, p. 134-144, 2000.

CARVALHO, J. Logística e Gestão da Cadeia de Abastecimento, Lisboa, Edições Sílabo, Ltda.2010,

COOPER, M.; LAMBERT, D. \& PAGH, J. Supply chain management: more than a new name for logistics. The International Journal of Logistics Management, v.8, n.1, p. 1-14, 1997.

CHOW, W.; MADU, C.; KUEI, C-H., LU, M.; LIN, C. \& TSENG, H. Supply chain management in the U.S. and Taiwan: an empirical study. The International Journal of Management Science, v.36, p.665-679, 2008.

CROXTON, K.; GARCÍA-DASTUGUE, S. \& LAMBERT, D. The supply chain management process. International Journal of Logistics Management, v. 12, n.2, p. 13, 2001.

CROXTON, K.; GARCÍA-DASTUGUE, S. \& LAMBERT, D. The supply chain management process. International Journal of Logistics Management, v. 26, n.1, p. 25-51, 2005. 
DALGIC, Y., LAZAKIS, I., TURAN, O. \& JUDAH, S. Investigation of optimum jack-up vessel chartering strategy for offshore wind farm O\&M activities. Ocean Engineering. 95, p.106-115, 2015.

DOBLER, D.; BURT, D. Purchasing and supply management: Text and cases. 6 ed., New York: McGraw-Hill. 1996. p. 190-208.

DUBOIS, A. Strategic cost management across boundaries of firms Industrial Marketing Management, 32, p.365-374, 2003.

DUBOIS, A.; PEDERSEN, A.C. Why relationships do not fit into purchasing portfolio models: a comparison between the portfolio and industrial network approaches. European Journal of Purchasing \& Supply Management, 8, p.35-42. 2002.

ELLRAM, L.M. Supply's management's involvement in the target costing process. European Journal of Purchasing \& Supply, p. 235-244, 2002.

ELLRAM L. \& CARR, A. Strategic purchasing: A history and review of the literature. International Journal of Purchasing and Materials Management, 30, p. 10-18, 1994.

FAGGERHOLT, K.; CRISTIANSEN, M.; HVATTUM, L.; JOHNSEN, T., $\mathrm{VABO}, \mathrm{J}$. A decision support methodology for strategic planning in maritime transportation. Omega. 38, p. 465-474, 2010.

HANDFIELD, R.B.; SROUFE, R.; WALTON, S. Integrating environmental management and supply chain strategies. Business Strategy and the Environment (1), 1-19, 2005.

HESPING, F. \& SCHIELE, H. Purchasing strategy development: A multilevel review. Journal of Purchasing \& Supply Management. 21, p.138150, 2015.

IMO - International Maritime Organization. The Role and Importance of International Shipping. Disponível em: <www.imo.org $>$. Acesso em 13/04/2015. 
Lei 9432/97. Dispõe sobre a ordenação do transporte aquaviário e dá outras providências. Disponível em http://www.planalto.gov.br/ccivil 03/leis/19432.htm. Acesso em 09/06/2015.

JIA, F., LAMMING, R., SARTOR, M., ORZES, G. \& NASSIMBENI, G. Global purchasing strategy and International Purchasing Offices: Evidence from case studies. International Journal of Production Economics, 154, p. 284-298, 2014.

KNIGHT, L., TU, Y. \& PRESTON, J. Integrating skills profiling and purchasing portfolio management: An opportunity for building purchasing capability. International Journal of Production Economics, 147, p.271283, 2014.

KRALJIC, P. Purchasing must become supply management, Harvard Business Review, v.61, n.5, p.109-117, setembro-outubro, 1983.

LAMBERT, D. The eight essential supply chain management process, Supply Chain Management Review, v. 8, n. 6, p. 18, 2004.

LAMBERT, D. \& COOPER, M. Issues in supply chain management. Industrial Marketing Management, v. 29, n. 1, p. 65-83, 2000.

LAMBERT, D.; COOPER, M. \& PAGH, J. Supply chain management: implementation issues and research opportunities. The International Journal of Logistics Management, v.9, n.2, p. 1-19, 1998.

LYSONS, K. \& FARRINGTON, B. Purchasing and supply chain management. 7 ed., Person Education, 2006.

MELNYK , S., LUMMUS, R., VOKURKA, R., BURNS, J. \& SANDOR, J. Mapping the future of supply chain management: a Delphi study. International Journal of Production Research, 47(16), 4629-4653, 2009. 
METTERS, R. A case study of national culture and offshoring services. International Journal of Operational and Production Management. 28, 727-747, 2008.

MIKALEF, P.; PATELI, A.; BATENBURG, R. \& WETERING, R. Investigating the impact of procurement alignment on supply chain management performance. Procedia Technology, v.9, p. 310-319, 2013.

MIOCEVIC, D. Organization buying effectiveness in supply chain contexto: Conceptualization and empirical assessmment. Jornal of Purchasing \& Supply Management, v.17, p.246-255, 2011.

MONCZKA, R.; TRENT, R. \& HANDFIELD, R. Purchasing and supply management. 3 ed., Ohio: Thomson South-Western, 2005.

MONCZKA, R., TRENT, R. \& PETERSEN, K. Getting on track to better. Global Sourcing Supply Chain Management Review, 12 (2), p. 46-53, 2008.

NARASIMHAN, R; DAS, A. - An empirical examination of sourcing's role in developing manufacturing flexibilites. International Journal of Production Research, v.38 n. 4, p. 875-893, 2000.

NELLORE, R. \& SÖDERQUIST, K. Portfolio approaches to procurement: analysing the missing link to specifications. Long Range Planning, v. 33, n.2, p.254-267, 2000.

NOLLET J.; PONCE S. \& CAMPBELL M. About strategy and strategies in supply management. Journal of Purchasing and Supply Management. 11, p.129-140, 2005.

NOVAES, A. Logística e gerenciamento da cadeia de distribuição: estratégia, operação e avaliação. 3 ed. Rio de Janeiro: Elsevier, 2007.

OLSEN, R. F.; ELLRAM, L. M. A Portfolio Approach to Supplier Relationships. Industrial Marketing Management, v. 26, p. 101-113. 1997. 
PAGELL, M.; WU, Z. Building a More Complete Theory of Sustainable Supply Chain Management Using Case Studies of Ten Exemplars. Journal of Supply Chain Management, 45, p. 37-56. 2009.

PAZIRANDEH, A \& NORMANN, A. An interrelation model of power and purchasing strategies: A study of vaccine purchasing for developing countries. 20, p.41-53, 2014.

PEMER, F., SIEWEKE, J., WERR, A.,BIRKNER, S. \& MOHE, M. The cultural embeddedness of professional service purchasing - A comparative study of German and Swedish companies. Journal of Purchasing \& Supply Management, 20, p.273-285, 2014.

PIRES, I. Gestão da cadeia de suprimento: conceitos, estratégias, práticas e casos - Supply chain management. São Paulo: Editora Atlas S.A., 2004.

PORTER, M. How competitive forces shape strategy. Harvard Business Review, March-April, p.137-145, 1979.

PORTER, M. Estratégia Competitiva - Técnicas para análise de indústrias e da concorrência. 7 ed., Rio de Janeiro: Campus Ltda., 1986.

PRASAD, S.; BABBAR, S. International operations management research. Journal of Operations Management 18, p.209-247, 2000.

PLATTS, K., PROBERT, D. \& CAÑES, L. Make vs. buy decisions: A process incorporating multi attribute decision-making. International Journal of Production Economics, 77, p. 247-257, 2002.

QUINN, J.; HILMER, F. Strategic outsourcing. Sloan Management Review, p. 43-55, Verão, 1994.

SALGUES, 2002. Contratos de afretamento e transporte no Direito Marítimo. Disponível em http://jus.com.br/artigos/4022/contratos-deafretamento-e-transporte-no-direito-maritimo. Acesso em 12/06/2015. 
SARACENI, P. Transporte marítimo de petróleo e derivados. Rio de Janeiro: Interciência, 2006.

SMEDLUND, A., Identification and management of high-potential professional services. Journal of Management and Decision.46, p.864-87, 2008.

STOCK, J. \& BOYER, S. Developing a consensus definition of a supply chain management: a quality study. International Journal of Phisical Distribution \& Logistics Management, 39(8), p. 690-711, 2009.

SUKATI, I.; HAMID, A.; BAHARUN, R. \& YUSOFF, R. The study of supply chain management strategy and practices on supply chain performances. Procedia - Social and Behavioral Sciences, 40, p.225-233, 2012.

TSIONAS, M.; MERIKAS, A., MERIKA, A. Concentrated ownership and corporate performance revisited: The case of shipping. Transportation Research Part E. 48, p.843-852, 2012.

VERGARA, S. Projetos e relatórios de pesquisa em administração. $6^{\underline{a}}$ ed. p. 46-49. Rio de Janeiro. Atlas, 2005.

VOLDNES, G., GRONHAUG,K., NILSSEN,F., Satisfaction in buyer-seller relationships-influence of cultural differences. Industrial Marketing Management, 41, p.1081-1093, 2012.

WHEILER, K., Referrals between professional servisse provider. Industrial and Marketing Management. 16, p.191-200. 1987.

YIN, R. Estudo de caso: planejamento e métodos. 3a ed. Porto Alegre: Bookman, 2005.

ZHENG, J., KNIGHT, L., HARLAND, C., HUMBY, S. \& JAMES, K. An analysis of research into the future of purchasing and supply management. Journal of Purchasing and Supply Management, 13, p.69-83, 2007. 


\section{Apêndice I}

Lista de navios com os valores percentuais de cada navio em relação ao valor total contratado em TCP em análise neste estudo:

\begin{tabular}{|c|c|c|c|c|c|}
\hline NAVIO & ARMADOR & PAÍS & TIPO & DURAÇÃO & $\begin{array}{c}\text { \% Aluguel } \\
\text { em relação } \\
\text { ao total }\end{array}$ \\
\hline$A$ & Transpetro & Brasil & Claros & 11 & $0,41 \%$ \\
\hline$B$ & Transpetro & Brasil & Claros & 11 & $0,41 \%$ \\
\hline $\mathrm{C}$ & Transpetro & Brasil & Claros & 11 & $0,41 \%$ \\
\hline$D$ & Transpetro & Brasil & Claros & 11 & $0,41 \%$ \\
\hline$E$ & Transpetro & Brasil & Claros & 11 & $0,41 \%$ \\
\hline$F$ & Transpetro & Brasil & Claros & 11 & $0,41 \%$ \\
\hline $\mathrm{G}$ & Transpetro & Brasil & Claros & 11 & $0,41 \%$ \\
\hline $\mathrm{H}$ & Transpetro & Brasil & Claros & 11 & $0,41 \%$ \\
\hline 1 & Transpetro & Brasil & Claros/Escuros & 11 & $0,36 \%$ \\
\hline J & Transpetro & Brasil & Claros/Escuros & 11 & $0,36 \%$ \\
\hline K & Pancoast & Grécia & Claros & 36 & $0,41 \%$ \\
\hline$L$ & Norient & EUA & Claros & 32 & $0,38 \%$ \\
\hline M & Pancoast & Grécia & Claros & 36 & $0,37 \%$ \\
\hline $\mathrm{N}$ & Pancoast & Grécia & Claros & 36 & $0,36 \%$ \\
\hline $\mathrm{O}$ & Perosea Shipping & Grécia & Escuros & 24 & $0,35 \%$ \\
\hline$P$ & Sea Tanker Shipping & EUA & Claros & 36 & $0,31 \%$ \\
\hline$Q$ & Lavinia & Grécia & Escuros & 36 & $0,31 \%$ \\
\hline $\mathrm{R}$ & Empire & Grécia & Claros & 36 & $0,30 \%$ \\
\hline S & Lavinia & Grécia & Escuros & 36 & $0,30 \%$ \\
\hline $\mathrm{T}$ & Empire & Grécia & Escuros & 36 & $0,30 \%$ \\
\hline$U$ & White Rose & Turquia & Claros & 36 & $0,20 \%$ \\
\hline $\mathrm{V}$ & Transpetro & Brasil & Claros & 12 & $0,59 \%$ \\
\hline W & Transpetro & Brasil & Claros & 11 & $0,59 \%$ \\
\hline$x$ & Transpetro & Brasil & Claros & 6 & $0,59 \%$ \\
\hline Y & Transpetro & Brasil & Escuros & 11 & $0,59 \%$ \\
\hline$z$ & Transpetro & Brasil & Claros & 11 & $0,56 \%$ \\
\hline $\mathrm{AA}$ & Transpetro & Brasil & Claros & 11 & $0,56 \%$ \\
\hline$A B$ & Transpetro & Brasil & Claros & 11 & $0,56 \%$ \\
\hline$A C$ & Transpetro & Brasil & Claros & 11 & $0,34 \%$ \\
\hline$A D$ & Transpetro & Brasil & Claros & 11 & $0,34 \%$ \\
\hline$A E$ & Transpetro & Brasil & Claros & 11 & $0,34 \%$ \\
\hline$A F$ & Transpetro & Brasil & Claros & 11 & $0,34 \%$ \\
\hline$A G$ & Transpetro & Brasil & Escuros & 11 & $0,34 \%$ \\
\hline $\mathrm{AH}$ & Flumar & Brasil & Claros & 12 & $0,79 \%$ \\
\hline $\mathrm{Al}$ & Great Eastern & Índia & Claros & 60 & $0,43 \%$ \\
\hline AJ & Tsakos & Grécia & Claros/Escuros & 60 & $0,43 \%$ \\
\hline AK & Livanos & Grécia & Claros & 36 & $0,42 \%$ \\
\hline$A L$ & Empire & Grécia & Claros & 36 & $0,42 \%$ \\
\hline AM & Magnificent Shipping Inc & Grécia & Claros & 36 & $0,41 \%$ \\
\hline
\end{tabular}




\section{Continuação}

\begin{tabular}{|c|c|c|c|c|c|}
\hline NAVIO & ARMADOR & PAís & TIPO & DURAÇÃo & $\begin{array}{c}\text { \% Aluguel } \\
\text { em relação } \\
\text { ao total }\end{array}$ \\
\hline AN & D’Amico & Irlanda & Claros & 36 & $0,41 \%$ \\
\hline $\mathrm{AO}$ & Torm & Dinamarca & Claros & 12 & $0,41 \%$ \\
\hline AP & Torm & Dinamarca & Claros & 12 & $0,41 \%$ \\
\hline$A Q$ & घka & Grécia & Claros & 12 & $0,41 \%$ \\
\hline$A R$ & Thomasos & Grécia & Claros & 36 & $0,41 \%$ \\
\hline AS & NYK & Reino Unido & Claros & 36 & $0,40 \%$ \\
\hline AT & Styga Compania Naviera & Grécia & Claros & 36 & $0,40 \%$ \\
\hline$A U$ & Norient & EUA & Claros & 36 & $0,40 \%$ \\
\hline$A V$ & Livanos & Grécia & Claros & 36 & $0,40 \%$ \\
\hline AW & Eka & Grécia & Claros & 36 & $0,40 \%$ \\
\hline$A X$ & UPT & Alemanha & Claros & 36 & $0,40 \%$ \\
\hline AY & Ilhas Seychelles Petroleum & \begin{tabular}{|l|} 
Inas Seychelles \\
\end{tabular} & Claros & 36 & $0,40 \%$ \\
\hline$A Z$ & Mantinia Shipping CO. SA & Grécia & Claros & 36 & $0,40 \%$ \\
\hline BA & Thomasos & Grécia & Claros & 36 & $0,40 \%$ \\
\hline BB & छka & Grécia & Claros & 36 & $0,40 \%$ \\
\hline $\mathrm{BC}$ & Livanos & Grécia & Claros & 36 & $0,40 \%$ \\
\hline $\mathrm{BD}$ & FSL Países Baixos B.V. & Países Baixos & Claros & 36 & $0,40 \%$ \\
\hline $\mathrm{BE}$ & घka & Grécia & Claros & 36 & $0,40 \%$ \\
\hline $\mathrm{BF}$ & Tanker Shipping Europe & Reino Unido & Claros & 36 & $0,40 \%$ \\
\hline$B G$ & छka & Grécia & Claros/Escuros & 36 & $0,40 \%$ \\
\hline $\mathrm{BH}$ & FSL Países Baixos B.V. & Países Baixos & Claros/Escuros & 36 & $0,40 \%$ \\
\hline $\mathrm{BI}$ & Tsakos & Grécia & Claros/Escuros & 36 & $0,40 \%$ \\
\hline BJ & Great Eastern & Índia & Claros/Escuros & 36 & $0,40 \%$ \\
\hline BK & Aegian & Grécia & Claros & 36 & $0,40 \%$ \\
\hline $\mathrm{BL}$ & Tsakos & Grécia & Escuros & 36 & $0,40 \%$ \\
\hline BM & Navig Europe Ltd & Reino Unido & Claros & 36 & $0,39 \%$ \\
\hline $\mathrm{BN}$ & Transpetro & Brasil & Aliviador & 144 & $1,36 \%$ \\
\hline $\mathrm{BO}$ & Transpetro & Brasil & Aliviador & 144 & $1,36 \%$ \\
\hline $\mathrm{BP}$ & Lauritzen & Dinamarca & Aliviador & 60 & $1,10 \%$ \\
\hline $\mathrm{BQ}$ & Transpetro & Brasil & Claros/Escuros & 11 & $0,36 \%$ \\
\hline $\mathrm{BR}$ & Transpetro & Brasil & Claros/Escuros & 11 & $0,36 \%$ \\
\hline BS & Livanos & Grécia & Escuros & 36 & $0,52 \%$ \\
\hline BT & Livanos & Grécia & Escuros & 36 & $0,52 \%$ \\
\hline $\mathrm{BU}$ & Livanos & Grécia & Escuros & 36 & $0,52 \%$ \\
\hline $\mathrm{BV}$ & Livanos & Grécia & Escuros & 36 & $0,52 \%$ \\
\hline BW & Tsakos & Grécia & Escuros & 24 & $0,47 \%$ \\
\hline $\mathrm{BX}$ & Tsakos & Grécia & Escuros & 24 & $0,47 \%$ \\
\hline BY & Sanko Line & JAPAN & Escuros & 36 & $0,46 \%$ \\
\hline BZ & छka & Grécia & Escuros & 36 & $0,51 \%$ \\
\hline $\mathrm{CA}$ & Maersk & Dinamarca & Escuros & 36 & $0,51 \%$ \\
\hline $\mathrm{CB}$ & Dorian Hellas & Grécia & Escuros & 36 & $0,51 \%$ \\
\hline $\mathrm{CC}$ & घka & Grécia & Escuros & 36 & $0,51 \%$ \\
\hline$C D$ & Great Eastern & Índia & Escuros & 36 & $0,46 \%$ \\
\hline CE & Almi Tankers & Grécia & Escuros & 36 & $0,45 \%$ \\
\hline $\mathrm{CF}$ & Maersk & Dinamarca & Escuros & 30 & $0,45 \%$ \\
\hline$C G$ & LR2 Pool & Dinamarca & Escuros & 30 & $0,45 \%$ \\
\hline $\mathrm{CH}$ & Almi Tankers & Grécia & Escuros & 36 & $0,43 \%$ \\
\hline $\mathrm{Cl}$ & Transpetro & Brasil & Aliviador & 156 & $1,52 \%$ \\
\hline Cu & Transpetro & Brasil & Aliviador & 144 & $1,52 \%$ \\
\hline CK & Transpetro & Brasil & Aliviador & 144 & $1,52 \%$ \\
\hline
\end{tabular}


Continuação

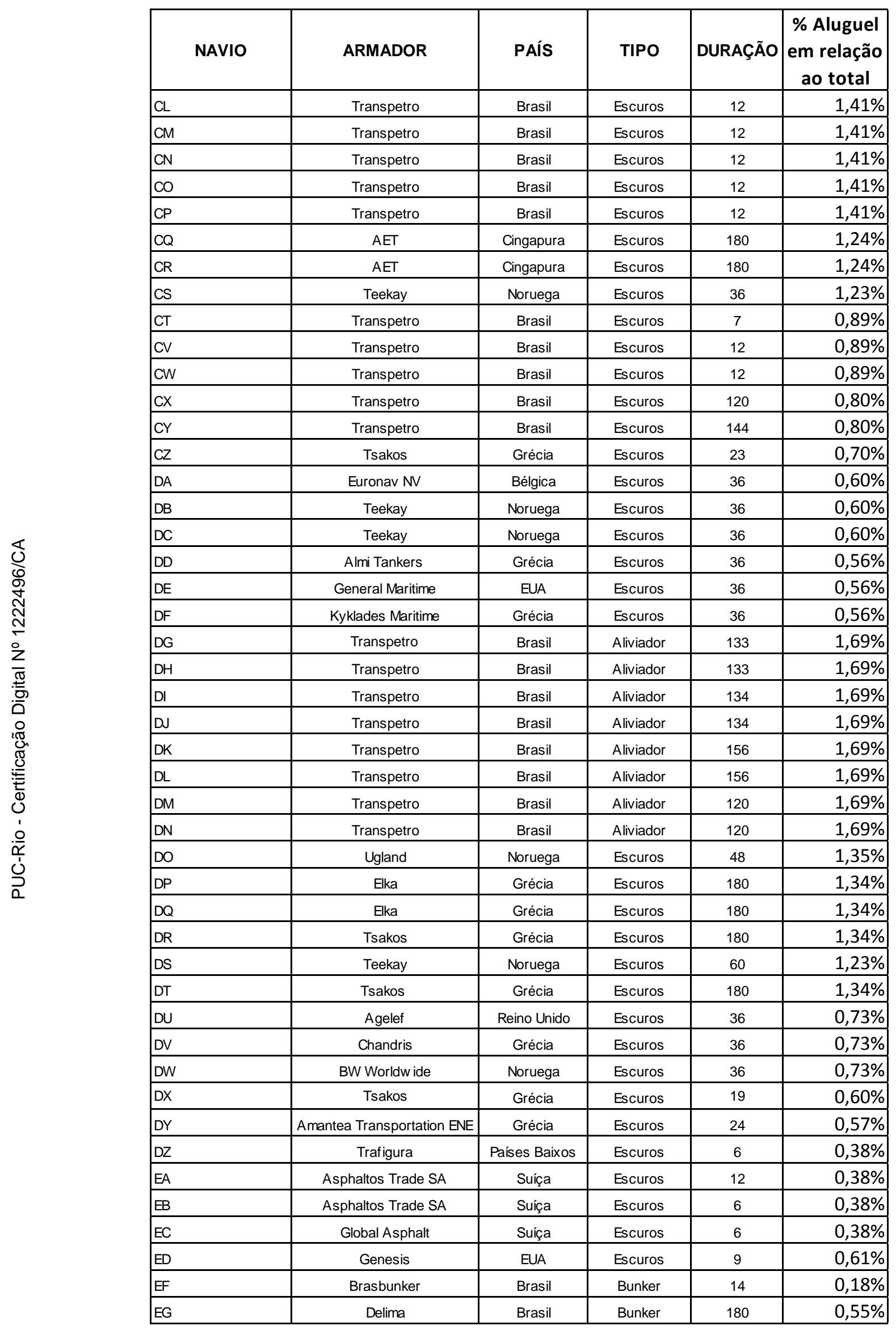


Continuação

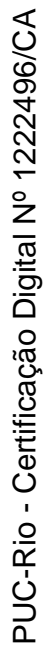

\begin{tabular}{|c|c|c|c|c|c|}
\hline NAVIO & ARMADOR & PAís & TIPO & DURAÇÃO & $\begin{array}{c}\text { \% Aluguel } \\
\text { em relação } \\
\text { ao total }\end{array}$ \\
\hline EH & Navegação Guarita & Brasil & Bunker & 6 & $0,15 \%$ \\
\hline El & Perosea Shipping & Grécia & Bunker & 24 & $0,35 \%$ \\
\hline EJ & Medtankers & Grécia & Bunker & 36 & $0,32 \%$ \\
\hline EK & Spring Marine Management & Grécia & Bunker & 24 & $0,32 \%$ \\
\hline EL & Brasbunker & Brasil & Bunker & 48 & $0,26 \%$ \\
\hline EM & Sinanju Marine Service Pte & Grécia & Bunker & 12 & $0,09 \%$ \\
\hline EM & Vitol S.A & Suíça & GLP & 36 & $0,40 \%$ \\
\hline EM & Vitol S.A & Suíça & GLP & 12 & $0,36 \%$ \\
\hline EO & Vitol S.A & Suíça & GLP & 12 & $0,36 \%$ \\
\hline EP & Stealth & Grécia & GLP & 12 & $0,36 \%$ \\
\hline EQ & Stealth & Grécia & GLP & 36 & $0,33 \%$ \\
\hline ER & Stealth & Grécia & GLP & 36 & $0,33 \%$ \\
\hline ES & Stealth & Grécia & GLP & 36 & $0,33 \%$ \\
\hline$E T$ & Stealth & Grécia & GLP & 6 & $0,31 \%$ \\
\hline EU & Petredec Ltd. & Reino Unido & GLP & 36 & $0,31 \%$ \\
\hline EV & Stealth & Grécia & GLP & 6 & $0,29 \%$ \\
\hline EW & Transpetro & Brasil & GLP & 11 & $0,41 \%$ \\
\hline EX & Transpetro & Brasil & GLP & 11 & $0,41 \%$ \\
\hline$E Y$ & Transpetro & Brasil & GLP & 11 & $0,41 \%$ \\
\hline EZ & Transpetro & Brasil & GLP & 11 & $0,35 \%$ \\
\hline FA & Transpetro & Brasil & GLP & 11 & $0,35 \%$ \\
\hline $\mathrm{FB}$ & Transpetro & Brasil & GLP & 11 & $0,35 \%$ \\
\hline $\mathrm{FC}$ & Maersk & Dinamarca & GLP & 36 & $0,71 \%$ \\
\hline FD & BW Gas & Noruega & GLP & 36 & $0,92 \%$ \\
\hline $\mathrm{FE}$ & Bw Green & Noruega & GLP & 36 & $0,83 \%$ \\
\hline
\end{tabular}




\section{Apêndice II}

Tabela de navios com posicionamento dos armadores na Matriz de Kraljic:

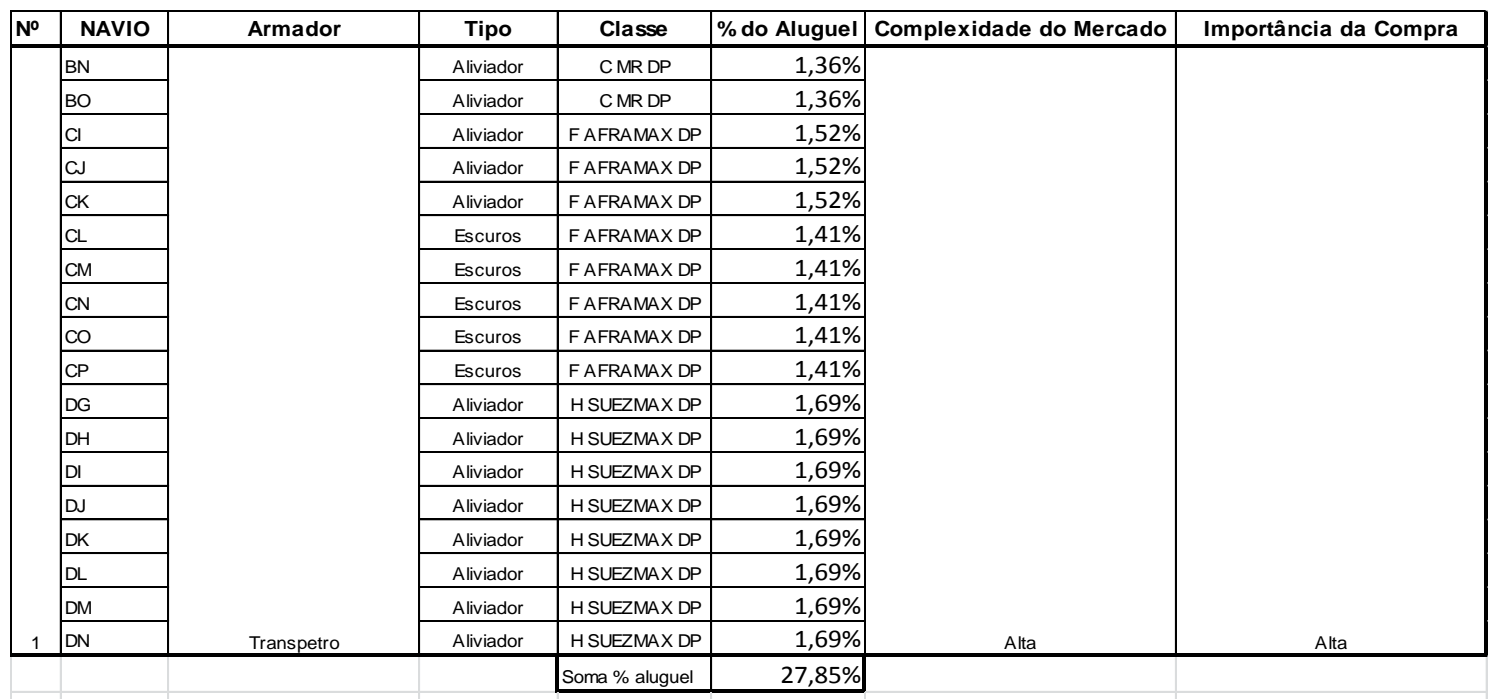

\begin{tabular}{|c|c|c|c|c|c|c|c|}
\hline № & NAVIO & Armador & Tipo & Classe & $\%$ do Aluguel & Complexidade do Mercado & Importância da Compra \\
\hline & A & & Claros & A HANDYMAX & $0,41 \%$ & & \\
\hline & $B$ & & Claros & A HANDYMAX & $0,41 \%$ & & \\
\hline & C & & Claros & A HANDYMAX & $0,41 \%$ & & \\
\hline & $\mathrm{D}$ & & Claros & A HANDYMAX & $0,41 \%$ & & \\
\hline & E & & Claros & A HANDYMAX & $0,41 \%$ & & \\
\hline & $\mathrm{F}$ & & Claros & A HANDYMAX & $0,41 \%$ & & \\
\hline & G & & Claros & A HANDYMAX & $0,41 \%$ & & \\
\hline & $\mathrm{H}$ & & Claros & A HANDYMAX & $0,41 \%$ & & \\
\hline & 1 & & Claros/Escuros & A HANDYMAX & $0,36 \%$ & & \\
\hline & J & & Claros/Escuros & A HANDYMAX & $0,36 \%$ & & \\
\hline & $\mathrm{v}$ & & \begin{tabular}{|l|} 
Claros \\
\end{tabular} & B MR & $0,59 \%$ & & \\
\hline & $\mathrm{w}$ & & Claros & BMR & $0,59 \%$ & & \\
\hline & $\mathrm{x}$ & & Claros & BMR & $0,59 \%$ & & \\
\hline & $Y$ & & Escuros & B MR & $0,59 \%$ & & \\
\hline & $z$ & & Claros & BMR & $0,56 \%$ & & \\
\hline & $\mathrm{AA}$ & & Claros & BMR & $0,56 \%$ & & \\
\hline & $A B$ & & Claros & BMR & $0,56 \%$ & & \\
\hline & $A C$ & & Claros & B MR & $0,34 \%$ & & \\
\hline & $A D$ & & Claros & BMR & $0,34 \%$ & & \\
\hline & $A E$ & & Claros & BMR & $0,34 \%$ & & \\
\hline & $\mathrm{AF}$ & & Claros & BMR & $0,34 \%$ & & \\
\hline & $A G$ & & Escuros & BMR & $0,34 \%$ & & \\
\hline & $\mathrm{BQ}$ & & Claros/Escuros & D PANAMAX & $0,36 \%$ & & \\
\hline & $B R$ & & Claros/Escuros & D PANAMAX & $0,36 \%$ & & \\
\hline & Ст & & \begin{tabular}{|l|} 
Escuros \\
\end{tabular} & G SUEZMAX & $0,89 \%$ & & \\
\hline & $\mathrm{CV}$ & & Escuros & G SUEZMAX & $0,89 \%$ & & \\
\hline & CW & & Escuros & G SUEZMAX & $0,89 \%$ & & \\
\hline & $C x$ & & Escuros & G SUEZMAX & $0,80 \%$ & & \\
\hline & $\mathrm{CY}$ & & Escuros & G SUEZMAX & $0,80 \%$ & & \\
\hline & EW & & GLP & L Pressurizado & $0,41 \%$ & & \\
\hline & EX & & GLP & L Pressurizado & $0,41 \%$ & & \\
\hline & $\mathrm{EY}$ & & GLP & L Pressurizado & $0,41 \%$ & & \\
\hline & Ez & & GLP & L Pressurizado & $0,35 \%$ & & \\
\hline & FA & \multirow[b]{2}{*}{ Transpetro } & GLP & L Pressurizado & $0,35 \%$ & & \\
\hline 2 & $F B$ & & GLP & L Pressurizado & $0,35 \%$ & Baixa & Alta \\
\hline
\end{tabular}




\section{Continuação}

\begin{tabular}{|c|c|c|c|c|c|c|c|}
\hline № & NAVIO & Armador & Tipo & Classe & $\%$ do Aluguel & Complexidade do Mercado & Importância da Compra \\
\hline \multirow{3}{*}{3} & $\mathrm{DP}$ & \multirow[b]{2}{*}{ Eka } & Escuros & H SUEZMAX DP & $1,34 \%$ & \multirow[b]{2}{*}{ Alta } & \multirow[b]{2}{*}{ Alta } \\
\hline & DQ & & Escuros & H SUEZMAX DP & $1,34 \%$ & & \\
\hline & & & & Soma \% aluguel & $2,68 \%$ & & \\
\hline
\end{tabular}

\begin{tabular}{|c|c|c|c|c|c|c|c|}
\hline № & NAVIO & Armador & Tipo & Classe & $\%$ do Aluguel & Complexidade do Mercado & Importância da Compra \\
\hline \multirow[b]{7}{*}{4} & $A Q$ & \multirow[b]{7}{*}{$\boxminus \mathrm{ka}$} & Claros & B MR & $0,41 \%$ & \multirow[b]{7}{*}{ Baixa } & \multirow[b]{7}{*}{ Alta } \\
\hline & AW & & Claros & B MR & $0,40 \%$ & & \\
\hline & BB & & Claros & B MR & $0,40 \%$ & & \\
\hline & $\mathrm{BE}$ & & Claros & B MR & $0,40 \%$ & & \\
\hline & $B G$ & & Claros/Escuros & B MR & $0,40 \%$ & & \\
\hline & $\mathrm{BZ}$ & & Escuros & EAFRAMAX & $0,51 \%$ & & \\
\hline & $\mathrm{cc}$ & & Escuros & EAFRAMAX & $0,51 \%$ & & \\
\hline & & & & Soma \% aluguel & $3,02 \%$ & & \\
\hline & & & & & & & \\
\hline № & NAVIO & Armador & Tipo & Classe & $\%$ do Aluguel & Complexidade do Mercado & Importância da Compra \\
\hline \multirow{3}{*}{5} & DR & \multirow{3}{*}{ Tsakos } & Escuros & H SUEZMAX DP & \begin{tabular}{r|}
$1,34 \%$ \\
\end{tabular} & \multirow[b]{2}{*}{ Alta } & \multirow[b]{2}{*}{ Alta } \\
\hline & DT & & Escuros & H SUEZMAX DP II & $1,34 \%$ & & \\
\hline & & & & Soma \% aluguel & $2,68 \%$ & & \\
\hline
\end{tabular}

\begin{tabular}{|c|c|c|c|c|c|c|c|}
\hline № & NAVIO & Armador & Tipo & Classe & $\%$ do Aluguel & Complexidade do Mercado & Importância da Compra \\
\hline \multirow[b]{7}{*}{6} & AJ & \multirow[b]{7}{*}{ Tsakos } & Claros/Escuros & B MR & $0,43 \%$ & \multirow[b]{7}{*}{ Baixa } & \multirow[b]{7}{*}{ Alta } \\
\hline & $\mathrm{BI}$ & & Claros/Escuros & B MR & $0,40 \%$ & & \\
\hline & $\mathrm{BL}$ & & Escuros & B MR & $0,40 \%$ & & \\
\hline & BW & & Escuros & D PANAMAX & $0,47 \%$ & & \\
\hline & $\mathrm{BX}$ & & Escuros & D PANAMAX & $0,47 \%$ & & \\
\hline & $\mathrm{CZ}$ & & Escuros & G SUEZMAX & $0,70 \%$ & & \\
\hline & $\mathrm{DX}$ & & Escuros & IVLCC & $0,60 \%$ & & \\
\hline & & & & Soma \% aluguel & $3,46 \%$ & & \\
\hline
\end{tabular}

\begin{tabular}{|c|c|c|c|c|c|c|c|}
\hline № & NAVIO & Armador & Tipo & Classe & $\%$ do Aluguel & Complexidade do Mercado & Importância da Compra \\
\hline \multirow[b]{7}{*}{7} & AK & \multirow[b]{7}{*}{ Livanos } & Claros & B MR & $0,42 \%$ & \multirow[b]{7}{*}{ Baixa } & \multirow[b]{7}{*}{ Alta } \\
\hline & AV & & Claros & $\mathrm{B} M \mathrm{MR}$ & $0,40 \%$ & & \\
\hline & $\mathrm{BC}$ & & Claros & $\mathrm{B} M \mathrm{MR}$ & $0,40 \%$ & & \\
\hline & BS & & Escuros & DPANAMAX & $0,52 \%$ & & \\
\hline & BT & & Escuros & D PANAMAX & $0,52 \%$ & & \\
\hline & BU & & Escuros & D PANAMAX & $0,52 \%$ & & \\
\hline & BS & & Escuros & D PANAMAX & $0,52 \%$ & & \\
\hline
\end{tabular}

\begin{tabular}{|l|l|l|l|l|r|r|r|}
\hline No & NAVIO & Armador & Tipo & Classe & \% do Aluguel & Complexidade do Mercado & Importância da Compra \\
\hline \multirow{3}{*}{8} & CS & & Escuros & F AFRAMAX DP & $1,23 \%$ & & \\
\cline { 2 - 2 } & & & Escuros & HSUEZMAX DP & $1,23 \%$ & Alta & Alta \\
\hline
\end{tabular}

\begin{tabular}{|c|c|c|c|c|r|r|r|}
\hline No & NAVIO & Armador & Tipo & Classe & \% do Aluguel & Complexidade do Mercado & Importância da Compra \\
\hline \multirow{2}{*}{9} & DB & & Escuros & G SUEZMAX & $0,60 \%$ & & \\
\cline { 2 - 5 } & DC & Teekay & Escuros & G SUEZMAX & $0,60 \%$ & Baixa & Alta \\
\hline
\end{tabular}

\begin{tabular}{|c|c|c|c|c|c|c|c|}
\hline № & NAVIO & Armador & Tipo & Classe & $\%$ do Aluguel & Complexidade do Mercado & Importância da Compra \\
\hline \multirow{3}{*}{10} & $\mathrm{CQ}$ & \multirow[b]{2}{*}{ AET } & Escuros & F AFRAMAX DP & $1,24 \%$ & \multirow[b]{2}{*}{ Alta } & \multirow[b]{2}{*}{ Alta } \\
\hline & $\mathrm{CR}$ & & Escuros & F AFRAMAX DP & $1,24 \%$ & & \\
\hline & & & & Soma \% aluguel & $2,49 \%$ & & \\
\hline
\end{tabular}


Continuação

\begin{tabular}{|c|c|c|c|c|c|c|c|}
\hline № & NAVIO & Armador & Tipo & Classe & $\%$ do Aluguel & Complexidade do Mercado & Importância da Compra \\
\hline \multirow{7}{*}{11} & EP & \multirow[b]{6}{*}{ Stealth } & GLP & L Pressurizado & $0,36 \%$ & \multirow[b]{6}{*}{ Baixa } & \multirow[b]{6}{*}{ Alta } \\
\hline & EQ & & GLP & L Pressurizado & $0,33 \%$ & & \\
\hline & ER & & GLP & L Pressurizado & $0,33 \%$ & & \\
\hline & ES & & GLP & L Pressurizado & $0,33 \%$ & & \\
\hline & ET & & GLP & L Pressurizado & $0,31 \%$ & & \\
\hline & EV & & GLP & L Pressurizado & $0,29 \%$ & & \\
\hline & & & & Soma \% aluguel & $1,94 \%$ & & \\
\hline
\end{tabular}

\begin{tabular}{|c|c|c|c|c|c|c|c|}
\hline № & NAVIO & Armador & Tipo & Classe & $\%$ do Aluguel & Complexidade do Mercado & Importância da Compra \\
\hline \multirow[b]{3}{*}{12} & CA & \multirow[b]{3}{*}{ Maersk } & Escuros & EAFRAMAX & $0,51 \%$ & \multirow[b]{3}{*}{ Baixa } & \multirow[b]{3}{*}{ Alta } \\
\hline & $\mathrm{CF}$ & & Escuros & EAFRAMAX & $0,45 \%$ & & \\
\hline & FC & & GLP & MLGC & $0,71 \%$ & & \\
\hline
\end{tabular}

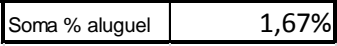

\begin{tabular}{|l|c|c|c|c|r|r|r|}
\hline No & NAVIO & Armador & Tipo & Classe & \% do Aluguel & Complexidade do Mercado & Importância da Compra \\
\hline \multirow{3}{*}{13} & EM & Vitol S.A & GLP & L Pressurizado & $0,40 \%$ & \\
\cline { 2 - 6 } & EM & Vitol S.A & GLP & L Pressurizado & $0,36 \%$ & \\
\cline { 2 - 5 } & EO & Vitol S.A & GLP & L Pressurizado & $0,36 \%$ & Baixa & Alta \\
\hline
\end{tabular}

\begin{tabular}{|l|r|}
\hline Soma $\%$ aluguel & $1,12 \%$ \\
\hline
\end{tabular}

\begin{tabular}{|c|c|c|c|c|c|c|c|}
\hline \multirow{2}{*}{ № } & NAVIO & Armador & Tipo & Classe & \% do Aluguel & Complexidade do Mercado & Importância da Compra \\
\cline { 2 - 7 } 14 & DO & Ugland & Escuros & H SUEZMAX DP & $1,35 \%$ & Alta & Alta
\end{tabular}

\begin{tabular}{|l|l|c|c|c|r|r|r|}
\hline No & NAVIO & Armador & Tipo & Classe & \% do Aluguel & Complexidade do Mercado & Importância da Compra \\
\hline \multirow{3}{*}{15} & K & Pancoast & Claros & A HANDYMAX & $0,41 \%$ & & \\
\cline { 2 - 5 } & M & Pancoast & Claros & A HANDYMAX & $0,37 \%$ & \\
\hline
\end{tabular}

\begin{tabular}{|c|c|c|c|c|c|c|c|}
\hline № & NAVIO & Armador & Tipo & Classe & \% do Aluguel & Complexidade do Mercado & Importância da Compra \\
\cline { 2 - 7 } 16 & BP & Lauritzen & Aliviador & C MR DP & $1,10 \%$ & Alta & Alta \\
\hline
\end{tabular}

\begin{tabular}{|l|l|c|c|c|r|r|r|}
\hline No & NAVIO & Armador & Tipo & Classe & \% do Aluguel & Complexidade do Mercado & Importância da Compra \\
\hline \multirow{3}{*}{17} & CE & Almi Tankers & Escuros & EAFRAMAX & $0,45 \%$ & \\
\cline { 2 - 6 } & CH & Almi Tankers & Escuros & EAFRAMAX & $0,43 \%$ & \\
\cline { 2 - 5 } & Almi Tankers & Escuros & G SUEZMAX & $0,56 \%$ & Baixa & Alta \\
\hline
\end{tabular}

\begin{tabular}{|l|r|r|}
\hline Soma \% aluguel & $1,45 \%$ &
\end{tabular}

\begin{tabular}{|l|l|c|c|c|r|r|r|}
\hline No & NAVIO & Armador & Tipo & Classe & \% do Aluguel & Complexidade do Mercado & Importância da Compra \\
\hline \multirow{3}{*}{18} & R & Empire & Claros & A HANDYMAX & $0,30 \%$ & & \\
\cline { 2 - 6 } & AL & Empire & Escuros & A HANDYMAX & $0,30 \%$ & \\
\cline { 2 - 6 } & Empire & Claros & B MR & $0,42 \%$ & Baixa & Alta \\
\hline
\end{tabular}


Continuação

\begin{tabular}{|c|c|c|c|c|c|c|c|}
\hline № & NAVIO & Armador & Tipo & Classe & $\%$ do Aluguel & Complexidade do Mercado & Importância da Compra \\
\hline 19 & BK & Aegian & Claros & B MR & $0,40 \%$ & Baixa & Baixa \\
\hline 20 & DU & Agelef & Escuros & IVLCC & $0,73 \%$ & Baixa & Baixa \\
\hline 21 & DY & Amantea Transportation ENE & Escuros & IVLCC & $0,57 \%$ & Baixa & Baixa \\
\hline 22 & EA & Asphaltos Trade SA & Escuros & J ASFALTO & $0,38 \%$ & Baixa & Baixa \\
\hline 22 & $E B$ & Asphaltos Trade SA & Escuros & J ASFALTO & $0,38 \%$ & Baixa & Baixa \\
\hline 23 & EF & Brasbunker & Bunker & K BUNKER & $0,18 \%$ & Baixa & Baixa \\
\hline 23 & 트 & Brasbunker & Bunker & K BUNKER & $0,26 \%$ & Baixa & Baixa \\
\hline 24 & FD & BW Gas & GLP & NVLGC & $0,92 \%$ & Baixa & Baixa \\
\hline 25 & $\mathrm{FE}$ & Bw Green & GLP & NVLGC & $0,83 \%$ & Baixa & Baixa \\
\hline 26 & DW & BW Worldwide & Escuros & IVLCC & $0,73 \%$ & Baixa & Baixa \\
\hline 27 & DV & Chandris & Escuros & IVLCC & $0,73 \%$ & Baixa & Baixa \\
\hline 28 & AN & D'Amico & Claros & B MR & $0,41 \%$ & Baixa & Baixa \\
\hline 29 & EG & Delima & Bunker & K BUNKER & $0,55 \%$ & Baixa & Baixa \\
\hline 30 & $\mathrm{CB}$ & Dorian Hellas & Escuros & EAFRAMAX & $0,51 \%$ & Baixa & Baixa \\
\hline 31 & DA & Euronav NV & Escuros & G SUEZMAX & $0,60 \%$ & Baixa & Baixa \\
\hline 32 & AH & Flumar & Claros & $\mathrm{B} M R$ & $0,79 \%$ & Baixa & Baixa \\
\hline 33 & $\mathrm{BD}$ & FSL Netherlands B.V. & Claros & B MR & $0,40 \%$ & Baixa & Baixa \\
\hline 33 & $\mathrm{BH}$ & FSL Netherlands B.V. & Claros/Escuros & B MR & $0,40 \%$ & Baixa & Baixa \\
\hline 34 & $\mathrm{DE}$ & General Maritime & \begin{tabular}{|l|} 
Escuros \\
\end{tabular} & G SUEZMAX & $0,56 \%$ & Baixa & Baixa \\
\hline 35 & ED & Genesis & Escuros & K BUNKER & $0,61 \%$ & Baixa & Baixa \\
\hline 36 & EC & Global Asphalt & Escuros & J ASFALTO & $0,38 \%$ & Baixa & Baixa \\
\hline 37 & Al & Great Eastern & Claros & B MR & $0,43 \%$ & Baixa & Baixa \\
\hline 37 & BJ & Great Eastern & Claros/Escuros & B MR & $0,40 \%$ & Baixa & Baixa \\
\hline 37 & $\mathrm{CD}$ & Great Eastern & Escuros & EAFRAMAX & $0,46 \%$ & Baixa & Baixa \\
\hline 38 & DF & Kyklades Maritime & Escuros & G SUEZMAX & $0,56 \%$ & Baixa & Baixa \\
\hline 39 & $Q$ & Lavinia & Escuros & A HANDYMAX & $0,31 \%$ & Baixa & Baixa \\
\hline 39 & s & Lavinia & Escuros & A HANDYMAX & $0,30 \%$ & Baixa & Baixa \\
\hline 40 & CG & LR2 Pool & Escuros & EAFRAMAX & $0,45 \%$ & Baixa & Baixa \\
\hline 41 & AM & Magnificent Shipping Inc & Claros & $\mathrm{BMR}$ & $0,41 \%$ & Baixa & Baixa \\
\hline 42 & $A Z$ & Mantinia Shipping CO. SA & Claros & B MR & $0,40 \%$ & Baixa & Baixa \\
\hline 43 & EJ & Medtankers & Bunker & K BUNKER & $0,32 \%$ & Baixa & Baixa \\
\hline 44 & EH & Navegação Guarita & Bunker & K BUNKER & $0,15 \%$ & Baixa & Baixa \\
\hline 45 & BM & Navig Europe Ltd & Claros & B MR & $0,39 \%$ & Baixa & Baixa \\
\hline 46 & $\mathrm{~L}$ & Norient & Claros & A HANDYMAX & $0,38 \%$ & Baixa & Baixa \\
\hline 46 & $A U$ & Norient & Claros & B MR & $0,40 \%$ & Baixa & Baixa \\
\hline 47 & AS & NYK & Claros & B MR & $0,40 \%$ & Baixa & Baixa \\
\hline 48 & $\mathrm{O}$ & Perosea Shipping & Escuros & A HANDYMAX & $0,35 \%$ & Baixa & Baixa \\
\hline 48 & E & Perosea Shipping & Bunker & K BUNKER & $0,35 \%$ & Baixa & Baixa \\
\hline 49 & EU & Petredec Ltd. & GLP & L Pressurizado & $0,31 \%$ & Baixa & Baixa \\
\hline 50 & BY & Sanko Line & Escuros & D PANAMAX & $0,46 \%$ & Baixa & Baixa \\
\hline 51 & $\mathrm{P}$ & Sea Tanker Shipping & Claros & A HANDYMAX & $0,31 \%$ & Baixa & Baixa \\
\hline 52 & AY & Seychelles Petroleum & Claros & B MR & $0,40 \%$ & Baixa & Baixa \\
\hline 53 & EM & Sinanju Marine Service Pte & Bunker & K BUNKER & $0,09 \%$ & Baixa & Baixa \\
\hline 54 & EK & Spring Marine Management & Bunker & K BUNKER & $0,32 \%$ & Baixa & Baixa \\
\hline 55 & AT & Styga Compania Naviera & Claros & B MR & $0,40 \%$ & Baixa & Baixa \\
\hline 56 & $\mathrm{BF}$ & Tanker Shipping Europe & Claros & B MR & $0,40 \%$ & Baixa & Baixa \\
\hline 57 & $\mathrm{AR}$ & Thomasos & Claros & B MR & $0,41 \%$ & Baixa & Baixa \\
\hline 57 & BA & Thomasos & Claros & B MR & $0,40 \%$ & Baixa & Baixa \\
\hline 58 & $\mathrm{AO}$ & Torm & Claros & B MR & $0,41 \%$ & Baixa & Baixa \\
\hline 58 & $\mathrm{AP}$ & Torm & Claros & B MR & $0,41 \%$ & Baixa & Baixa \\
\hline 59 & DZ & Trafigura & Escuros & J ASFALTO & $0,38 \%$ & Baixa & Baixa \\
\hline 60 & $A X$ & UPT & Claros & B MR & $0,40 \%$ & Baixa & Baixa \\
\hline \multirow[t]{2}{*}{614} & u & White Rose & Claros & A HANDYMAX & $0,20 \%$ & Baixa & Baixa \\
\hline & & & & Soma \% aluguel & $23,06 \%$ & & \\
\hline
\end{tabular}

